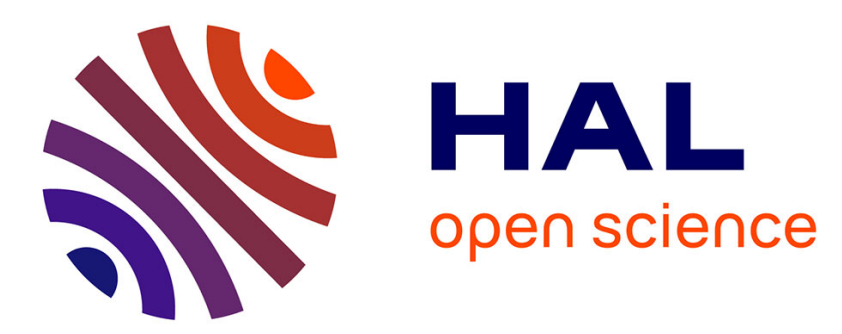

\title{
Fatty Acid Photodecarboxylase Is an Interfacial Enzyme That Binds to Lipid-Water Interfaces to Access Its Insoluble Substrate
}

Cyril Aselmeyer, Bertrand Légeret, Anaïs Bénarouche, Damien Sorigué, Goetz Parsiegla, Fred Beisson, Frédéric Carrière

\section{To cite this version:}

Cyril Aselmeyer, Bertrand Légeret, Anaïs Bénarouche, Damien Sorigué, Goetz Parsiegla, et al.. Fatty Acid Photodecarboxylase Is an Interfacial Enzyme That Binds to Lipid-Water Interfaces to Access Its Insoluble Substrate. Biochemistry, 2021, 10.1021/acs.biochem.1c00317 . hal-03381197

\author{
HAL Id: hal-03381197 \\ https://hal.science/hal-03381197
}

Submitted on 16 Oct 2021

HAL is a multi-disciplinary open access archive for the deposit and dissemination of scientific research documents, whether they are published or not. The documents may come from teaching and research institutions in France or abroad, or from public or private research centers.
L'archive ouverte pluridisciplinaire HAL, est destinée au dépôt et à la diffusion de documents scientifiques de niveau recherche, publiés ou non, émanant des établissements d'enseignement et de recherche français ou étrangers, des laboratoires publics ou privés. 


\title{
Fatty acid photodecarboxylase is an interfacial enzyme that binds to lipid-water interfaces to access its insoluble substrate
}

\author{
Cyril Aselmeyer $^{1,2}$, Bertrand Légeret ${ }^{2}$, Anaïs Bénarouche ${ }^{1}$, Damien Sorigué ${ }^{2}$, Goetz Parsiegla ${ }^{1}$, Fred \\ Beisson $^{2} *$ and Frédéric Carrière ${ }^{1} *$ \\ ${ }^{1}$ Aix Marseille Université, CNRS, UMR 7281 Bioénergétique et Ingénierie des Protéines, Marseille, France \\ ${ }^{2}$ CEA, CNRS, Aix Marseille Université, Biosciences and Biotechnologies Institute of Aix-Marseille (BIAM), UMR 7265, \\ CEA Cadarache, 13108 Saint-Paul-lez-Durance, France
}

KEYWORDS Biofuel; Hydrocarbons; Lipids; Liposome; Microemulsion ; Photoenzyme

\begin{abstract}
Fatty Acid Photodecarboxylase (FAP), one of the few natural photoenzymes characterized so far, is a promising biocatalyst for lipid-to-hydrocarbon conversion using light. However, the optimum supramolecular organization under which the fatty acid (FA) substrate should be presented to FAP has not been addressed. Using palmitic acid embedded in phospholipid liposomes, phospholipid-stabilized microemulsions and mixed micelles, we show that FAP displays a preference for FAs present in liposomes and at the surface of microemulsions. Adsorption kinetics onto phospholipid and galactolipid monomolecular films further suggests the ability of FAP to bind to and penetrate into membranes, with higher affinity in the presence of FAs. FAP structure reveals a potential interfacial recognition site with clusters of hydrophobic and basic residues surrounding the active site entrance. The resulting dipolar moment suggests the orientation of FAP at negatively charged interfaces. These findings provide important clues for the mode of action of FAP and the development of FAP-based bioconversion processes.
\end{abstract}

\section{INTRODUCTION}

Hydrocarbons find numerous applications in industry as synthons for organic chemistry and components of cosmetics, lubricants and transportation fuels $(1,2)$. Bio-based production of alkanes and alkenes is a major biotechnological aim because these compounds are currently mainly derived from petroleum. In the past ten years, a variety of enzymes forming hydrocarbons from aldehydes or non-esterified fatty acids (FAs) have been described (3-5). However, their in vitro applications as biocatalysts are often hampered by low turnovers and/or the need for electron donors(6-9).

Fatty Acid Photodecarboxylase (FAP; E.C. 4.1.1.106) is a new type of hydrocarbon-forming enzyme that has been identified in the green microalga Chlorella variabilis (10). FAP belongs to the family of glucose-methanol-choline (GMC) oxidoreductases and is, with DNA photolyase(11), light dependent protochorophyllide oxydoreductase(12) and photosystems reaction centers(13)., one of the few natural photoenzymes discovered to date FAP catalyzes the synthesis of alkanes and alkenes directly from FAs using a flavin-based light-dependent decarboxylation. No electron donor or additional cofactor is required. The crystal structure of Chlorella variabilis FAP (CvFAP) has shown that the flavin adenine dinucleotide (FAD) cofactor is located at the end of a hydrophobic tunnel containing the FA substrate(10). Recombinant CvFAP is active on C12 to C22 FAs dispersed in bulk with an optimum on palmitic acid
(C16). Formation of $\mathrm{C} 1$ to $\mathrm{C} 5$ hydrocarbons by CvFAP or CvFAP mutants has also been reported $(14,15)$.

The light-driven reaction catalyzed by FAP has triggered its use for alka(e)ne production in various microbial hosts(5). FAPbased production of hydrocarbons inside microbial cells has been reported in bacteria (10), microalgae/cyanobacteria (16) and yeast(17). Recently, it has also been shown that FAP can be used together with a medium-chain thioesterase to obtain a bacterial fuel cell system producing continuously volatile hydrocarbons that can be trapped in the gas phase of illuminated cultures(18). Besides microbial metabolic engineering, another potential and maybe easier application of FAP is its direct use as a biocatalyst. Cell lysates of E. coli expressing CvFAP have been used in combination with commercial lipases to convert triacylglycerols (TAG) from vegetable oils into hydrocarbons through the intermediate release of $\operatorname{FAs}(19,20)$. CvFAP was also used for the kinetic resolution of $\alpha$-amino acids and $\alpha$ hydroxy acids(21), in an enzymatic cascade for the formation of chiral secondary fatty alcohols(22) and for the synthesis of longchain aliphatic chiral amines and esters(23). FAP is therefore clearly a promising enzyme for a bio-based production of alk(a)enes and high-value chemicals.

Using FAP in vitro or in microorganisms to produce hydrocarbons will require optimizing not only the enzyme itself but also other parameters that may greatly affect FAP activity such as light intensity, quality and penetration in the reactors or 
the physical form under which FAs may be presented to FAP. This latter parameter has not been investigated so far.

Understanding how FAP interacts with FAs is all the more required since monomeric FAs are virtually insoluble in water where they form dispersions with considerable polymorphism, including dimers(24), micelles(25), nanotubes(26), vesicles(27,
28) and even oil droplets at low $\mathrm{pH}(29)$. Besides their selfassembly properties in water, FAs can interact with other lipids and amphiphiles to form various types of supramolecular assemblies such as oil droplets, lamellar phases (membranes and liposomes) and micellar aggregates (Figure1)(30, 31).
A
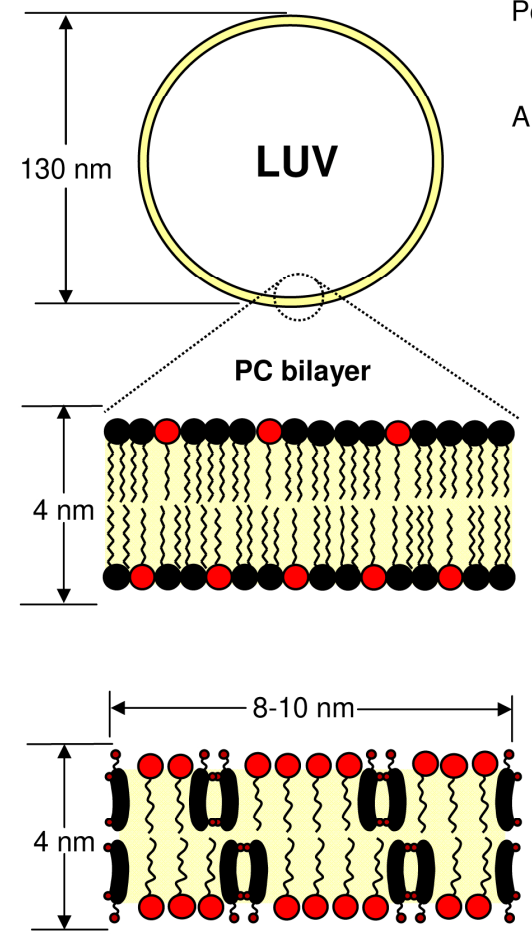

C

Disk-shaped mixed micelles
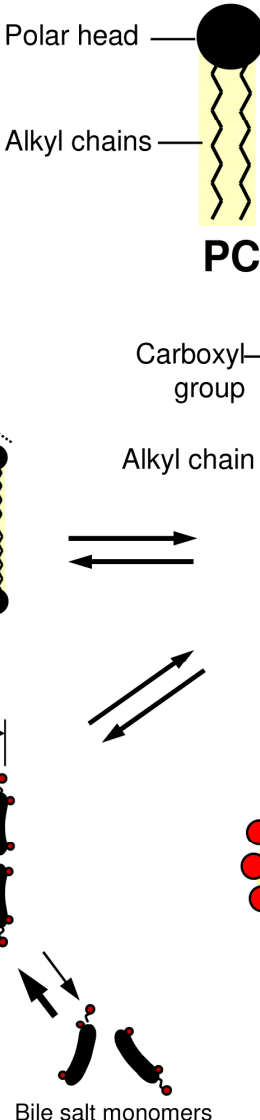

PC

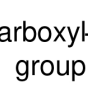

$-\}$

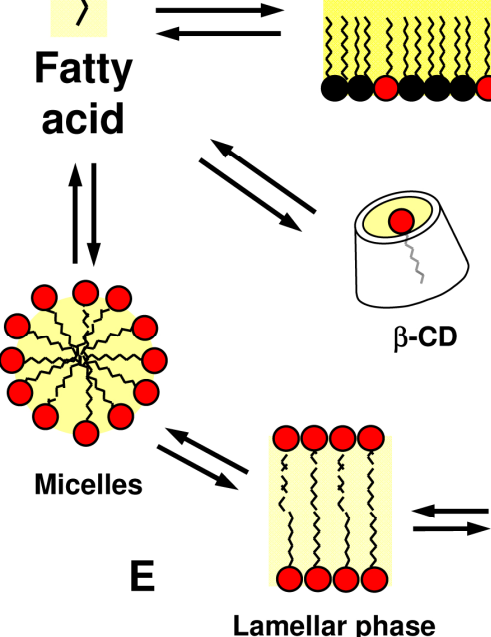

B

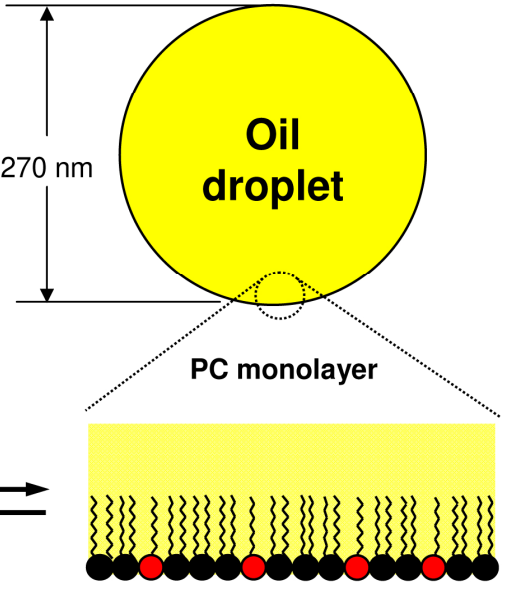

D

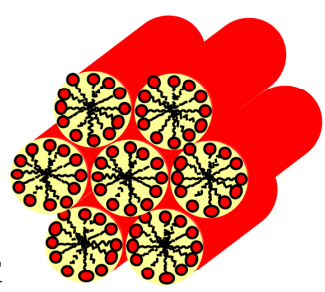

Hexagonal phase Liquid crystals

Figure 1. Schematic representation of FA partitioning in an aqueous environment containing other lipids and FA-binding molecules. (A) Large Unilamellar Vesicles (LUVs); (B) Phosphatidylcholine (PC)-stabilized oil-in-water emulsion; (C) Mixed micelles with amphiphiles like bile salts; (D) Complex with FA-binding molecules like $\beta$-cyclodextrin ( $\beta$-CD); (E) Self-aggregation in the form of micelles, lamellar or hexagonal phases when $\mathrm{pH}>\mathrm{pKa}$. Depending on parameters like $\mathrm{pH}$, counter ions and concentration, the non-esterified FA substrate of FAP can be present in these different assemblies, some of which may be in equilibrium.

These organized systems are essentially depending on the ionization state, the degree of unsaturation and the chain length of FAs, as well as on the presence of counter ions like calcium which can lead to the formation of soaps or interact with negatively charged polar heads of lipids at interfaces and thus affect surface potential(32-34).

Here we characterize CvFAP activity on FAs present at various lipid-water interfaces including liposomes, oil-in-water microemulsions and mixed micelles, or complexed to $\beta$ cyclodextrin or albumin. Results show that FAP acts as an interfacial enzyme able to bind to lipid-water interfaces to access insoluble long chain FAs.

\section{MATERIALS AND METHODS}

Lipids.

Palmitic acid (PA; $\geq 99 \%$; P0500) used for all assays of fatty acid photodecarboxylase (FAP) and preparation of mixed lipid assemblies, and heptadecanoic acid ( $\geq 98 \%$; H3500) used as internal standard were from Sigma-Aldrich. For Langmuir monolayer studies, egg yolk phosphatidylcholine (PC) $(>99 \%$ purity) was from Avanti Polar Lipids Inc.. 3-O-(6-O- $\alpha-D-$ galactopyranosyl- $\beta$-D-galactopyranosyl)-1,2-di-O-dodecanoylsn-glycerol (C12-DGDG) was synthesized according to Lafont 
et al. (35). Large unilamellar vesicles (LUVs) were prepared using Lipoid E PC S egg PC (99.2\% (w/w)) purchased from Lipoid AG (Steinhausen, Switzerland). Intralipid ${ }^{\mathrm{TM}} 20 \%$ containing $20 \%(\mathrm{w} / \mathrm{w})$ soybean oil and $1.2 \%(\mathrm{w} / \mathrm{w})$ egg PC was from Fresenius Kabi (Sèvres, France).

Lipids from thylakoid membranes were purified from Chlorella variabilis NC64A wild type strain as described in the Supporting Information.

\section{Other chemicals.}

All other chemicals, including $\mathrm{NaCl}, \mathrm{CaCl}_{2}$, Tris, EDTA, fatty acid-free bovine serum albumin (BSA), $\beta$-cyclodextrine ( $\beta$-CD), sodium taurodeoxycholate (NaTDC), sodium acetate and hexadecane, were purchased from Sigma-Aldrich and were BioXtra grade $(99.0 \%$ purity). Chloroform (anhydrous for analysis, stabilized with amylene), methanol and hexane of puriss grade were purchased from Carlo Erba Reactifs-SDS (Val-de-Reuil, France).

\section{Recombinant FAP production and purification.}

The DNA sequences corresponding to residues $62-654$ or 76654 of Chlorella variabilis FAP (corresponding to FAPv1 and FAPV2 respectively; see protein sequences in section 3. of Supporting information) were amplified from a synthetic gene codon-optimized for expression in $E$. coli and cloned into pLIC07 vector, which introduced downstream of the ATG start codon a cassette coding for a 6 His-tagged thioredoxin and a tobacco etch virus (TEV) protease-cleavage site. The recombinant FAPs were produced in E. coli and purified as described before for FAPv1 (10) and FAPv2 (36).

\section{Preparation of egg PC liposomes enriched in PA.}

Large unilamellar vesicles (LUV) were prepared by extrusion as follows. Egg PC (13.8 mg) was dissolved in $2 \mathrm{~mL}$ chloroformmethanol $(2: 1 \mathrm{v} / \mathrm{v})$. When required PA was added to the PC solution using a $50 \mathrm{mM}$ stock solution in chloroform-methanol $(2: 1 \mathrm{v} / \mathrm{v})$. The lipid solution in chloroform/methanol was then transferred to a 8-mL glass vial and the solvent was evaporated under a nitrogen flux in order to obtain a thin lipid film on the wall of the tube. Multi-lamellar vesicles (MLV) were first prepared by hydrating the lipid film with $5 \mathrm{~mL}$ of either Teorell Stenhagen universal buffer, at $\mathrm{pH}$ values ranging from 6.5 to 10 , or $150 \mathrm{mM}$ Bis-Tris-Propane (BTP), $100 \mathrm{mM} \mathrm{NaCl}, \mathrm{pH} 9$ buffer, for $1 \mathrm{~h}$ at $65^{\circ} \mathrm{C}$. Teorell Stenhagen universal buffer contained $33 \mathrm{mM}$ citric acid monohydrate, $33 \mathrm{mM}$ phosphoric acid, $100 \mathrm{mM} \mathrm{NaOH}, 16.7 \mathrm{mM}$ of boric acid. The $\mathrm{pH}$ was adjusted with $1 \mathrm{~N} \mathrm{HCl}$. LUVs were prepared by 5 extrusion cycles of the MLV solution through a $100 \mathrm{~nm}$ cut-off membrane using a Mini-extruder (Avanti Polar Lipids). The extrusion was performed at room temperature, i.e. above the Tm of Egg PC, according to Avanti's protocol. Each preparation of $5 \mathrm{~mL}$ contained an egg PC final concentration of $3.6 \mathrm{mM}$.

\section{Preparation of microemulsion enriched in PA.}

Intralipid® $20 \%$ was chosen as a well-defined and commercially available microemulsion, containing $20 \%(\mathrm{w} / \mathrm{w})$ purified soybean oil and $1.2 \%(\mathrm{w} / \mathrm{w})$ egg PC. Because of its opacity (milky aspect), it had to be diluted to ensure an efficient light transmittance in the reaction medium of FAP. A 20-fold dilution in BTP buffer $\mathrm{pH} 9$ was performed, which resulted in a
$1 \%(\mathrm{w} / \mathrm{w})$ soybean oil microemulsion containing $0.06 \%(\mathrm{w} / \mathrm{w})$ egg PC, i.e. an egg PC concentration of $0.78 \mathrm{mM}$, taking into account a mean molar mass of $770 \mathrm{~g} \cdot \mathrm{mol}^{-1}$ for egg PC. Microemulsions containing various amounts of PA (from 100 $\mu \mathrm{M}$ to $2 \mathrm{mM}$ final concentration) were prepared using a 100 mM PA stock in ethanol. The resulting dispersions were gently mixed by hand during 1 minute in order to homogenize PA distribution. A dynamic light scattering (DLS) analysis and a visual inspection were systematically performed to ensure that the dilution and PA addition did not lead to destabilization of the microemulsion and coalescence of oil droplets.

\section{Preparation of micellar solutions of PA.}

To prepare solutions with surfactant to PA molar ratio ranging from 2 to 16, surfactant solutions were first prepared separately by adding either Triton X-100 or NaTDC into BTP buffer, $\mathrm{pH} 9$, for final concentrations ranging from 2 to $16 \mathrm{mM}$. For each surfactant and concentration, PA $(80 \mu \mathrm{L}$ of a $100 \mathrm{mM}$ stock solution in ethanol) was poured into a $8-\mathrm{mL}$ glass tube and solvent was evaporated under gentle $\mathrm{N}_{2}$ flux. The PA dried film was then resuspended using the surfactant solution. In order to optimize the micellar dispersion of $\mathrm{PA}$, the solutions were heated at $65^{\circ} \mathrm{C}$ during 15 minutes, cooled down on ice for 5 minutes, and then sonicated for 15 minutes. These steps were repeated three times.

\section{FAP activity assays.}

Routine endpoint assays were performed in 1-mL transparent glass vials sealed using caps with septum in a room airconditioned at $20^{\circ} \mathrm{C} \pm 1{ }^{\circ} \mathrm{C}$. Teorell Stenhagen universal buffer was used for testing FAP activity at various $\mathrm{pH}$ values ranging from 6.5 to 10. BTP buffer at $\mathrm{pH} 9$ was used for all other assays. Reaction mixtures $(500 \mu \mathrm{L})$ typically contained around $100 \mathrm{nM}$ of FAD-containing purified enzyme (either FAPv1 or FAP v2 from stock solutions at $2 \mathrm{mg} \cdot \mathrm{mL}^{-1}$ ) and various contents of PA, either dispersed in bulk from stock solutions at 10 to $100 \mathrm{mM}$ in ethanol or present in LUVs and microemulsions prepared as described in the previous sections. Samples were shaken at 250 rpm during 15 min under LED-made white light at $2000 \mu \mathrm{mol}$ photons $\mathrm{m}^{-2} \cdot \mathrm{s}^{-1}$ (see Fig. S13 for experimental setup). They were then heated for 15 minutes at $95^{\circ} \mathrm{C}$ in order to stop the enzyme reaction, and further cooled down before an internal standard (45 nmol hexadecane from a $4.5 \mathrm{mM}$ stock solution in chloroform) and $\mathrm{NaOH}(100 \mu \mathrm{L}$ from a stock solution of $10 \mathrm{M})$ for saponification were added to the samples. Vials were vortexed for $5 \mathrm{~min}$ before being heated at $85^{\circ} \mathrm{C}$ for 90 minutes. Then, $500 \mu \mathrm{L}$ of hexane was added to each sample with a syringe and the vials were vortexed for $5 \mathrm{~min}$ in order to extract hydrocarbons. The organic phase was separated by centrifugation of the vials and collected for hydrocarbon analyses by GC-MS/FID.

FAP activity was expressed in $\mu$ moles of hydrocarbons produced per min and specific activity was estimated based on the amounts of FAP containing FAD, i.e. catalytically active. The amounts of FAD in FAP were estimated from the absorption at $467 \mathrm{~nm}$ using a molar extinction coefficient of 11,300. Correction factors of 0.53 and 0.71 were estimated for catalytically-active FAPv1 and FAPv2 versus the total amounts of these two purified proteins. Thus, for an average concentration of $160 \mathrm{nM}$ FAP per assay, the concentrations of active FAPv1 and FAPv2 were 86 and $114 \mathrm{nM}$, respectively. 
The enzymatic assays of FAP activity on PA in mixed micelles or complexed to $\beta-\mathrm{CD}$ or BSA were performed as described above, except that FAP activity was not estimated from the production of hydrocarbons but from the quantitative analysis by GC-MS/FID of the residual fatty acid substrate derived into methyl esters (FAMEs). This protocol was established after finding that hydrocarbon recovery from micellar solutions after saponification and hexane extraction was not reliable compared to other assays performed with FAs in bulk, LUVs and microemulsion. Changes in the experimental conditions are detailed in Supporting Information.

\section{GC-MS/FID analysis.}

Analyses by gas chromatography coupled to mass spectrometry and flame ionization detection (GC-MS/FID) were performed after transmethylation or saponification reactions. Analyzes were carried out on an Agilent 7890A gas chromatograph coupled to an Agilent 5975C mass spectrometer (simple quadrupole). A Zebron 7HG-G007-11 (Phenomenex) polar capillary column (length $30 \mathrm{~m}$, internal diameter $0.25 \mathrm{~mm}$, film thickness $0.25 \mu \mathrm{m}$ ) was used. Carrier gas was helium at 1 $\mathrm{mL} \cdot \mathrm{min}^{-1}$. Oven temperature was programmed with an initial 2min hold time at $60^{\circ} \mathrm{C}$, followed by a first ramp from $60^{\circ} \mathrm{C}$ to $150^{\circ} \mathrm{C}$ at $20^{\circ} \mathrm{C} \cdot \mathrm{min}^{-1}$ with a 5 -min hold time at $150^{\circ} \mathrm{C}$, and a second ramp from $150^{\circ} \mathrm{C}$ to $240^{\circ} \mathrm{C}$ at $6^{\circ} \mathrm{C} \cdot \mathrm{min}^{-1}$, and a final 3min hold time at $240^{\circ} \mathrm{C}$ (this temperature program was shortened for the analysis of saponification reactions). Samples were injected in splitless mode $(1 \mathrm{~min})$ at $250^{\circ} \mathrm{C}$. MS was run in full scan over 40-350 Th (electron impact ionization at $70 \mathrm{eV}$ ) and peaks were quantified based on the FID signal using the internal standards.

\section{FAP adsorption onto lipid monomolecular films spread at} the air-water interface.

Monomolecular film experiments were performed at room temperature $\left(20^{\circ} \mathrm{C}\right)$ using a KSV5000 Langmuir balance (KSV, Helsinki, Finland) monitored by KSV Device Server Software v.1.20 and equipped with a temperature sensor probe and a Wilhelmy blade connected to an electro-microbalance for measuring surface pressure. Monomolecular films were formed by spreading lipid solutions in chloroform over the surface of a polytetrafluoroethylene trough (volume, $8 \mathrm{~mL}$; surface area, $8.04 \mathrm{~cm} 2)$ filled with $100 \mathrm{mM} \mathrm{NaCl}, 21 \mathrm{mM} \mathrm{CaCl} 2,10 \mathrm{mM}$ Tris, $1 \mathrm{mM}$ Na.EDTA buffer, $\mathrm{pH}$ 8.0, prepared with Milli- $\mathrm{Q}^{\mathrm{TM}}$ water and filtered through a $0.25 \mu \mathrm{m}$ Millipore membrane. Lipid solutions in chloroform contained egg PC, C12-DGDG or thylakoid lipids from Chlorella variabilis at $0.1 \mathrm{mg} \cdot \mathrm{mL}^{-1}$. When mixed PA-lipid monolayers had to be formed, PA $(35.7 \%$ $\mathrm{mol} / \mathrm{mol}$ ) was first mixed with PC or C12-DGDG $(64.3 \%$ $\mathrm{mol} / \mathrm{mol}$ ) in chloroform Two types of experiments were performed: the first series aimed at measuring maximum variations in surface pressure $\left(\Delta \Pi_{m \text { ax }}\right)$ as a function of the initial surface pressure $\left(\Pi_{i}\right)$ of the film under which a known amount of FAP was injected. Various lipid amounts in chloroform were spread onto the buffer surface using a $10 \mu \mathrm{L}$ Hamilton syringe until the desired $\Pi_{i}$ was reached. After reaching a stable $\Pi_{i}$, FAP ( $8 \mu \mathrm{L}$ of a stock solution of FAP at $33.5 \mu \mathrm{M}$ ) was injected into the aqueous subphase with a $10 \mu \mathrm{L}$ Hamilton syringe, for a final concentration of $33.5 \mathrm{nM}$. Right after protein injection, the aqueous subphase was continuously stirred with a $5 \mathrm{~mm}$ magnetic bar rotating at $200 \mathrm{rpm}$. The surface pressure increase due to the adsorption/penetration of the protein onto the lipid monolayer was continuously recorded (every $5 \mathrm{~s}$ ) until the maximum surface pressure at equilibrium $\left(\Pi_{e}\right)$ was reached (Fig. $\mathrm{S} 13)$. Plotting the maximum surface pressure increase $\left(\Delta \Pi_{\max }=\right.$ $\left.\Pi_{e}-\Pi_{i}\right)$ as a function of $\Pi_{\mathrm{i}}$ allowed estimating the critical surface pressure of penetration $\left(\Pi_{c}\right)$ of FAP into the various lipid film tested, as the intercept between the linear regression curve and the $\Pi_{i}$-axis.

The second series of experiments aimed at determining adsorption rate $\left(k_{a}, \mathrm{M}^{-1} \mathrm{~s}^{-1}\right)$, desorption rate $\left(k_{d}, \mathrm{~s}^{-1}\right)$ and dissociation $\left(K_{D}, \mathrm{M}\right)$ constants for FAP adsorption onto PC and C12-DGDG monolayers in the absence and presence of PA. Adsorption kinetics were recorded for increasing amounts of FAP injected below films at an initial surface pressure of 10 $\mathrm{mN} \cdot \mathrm{m}^{-1}$ (Fig. S11). Final FAP concentration in the aqueous phase ranged from 2 to $33 \mathrm{nM}$, Adsorption curve $(\Delta \Pi=\mathrm{f}(t))$ fitting to Langmuir adsorption isotherm allowed us estimating $k_{a}$ and $k_{d}$, as previously described for lipases (37).

In all experiments, the $\mathrm{pH}$ of the aqueous subphase was adjusted at 8.0 in order to work with well establish conditions of stable monolayers $(37,38)$. Although this $\mathrm{pH}$ value is not the optimum for FAP activity ( $\mathrm{pH} \mathrm{9;} \mathrm{see} \mathrm{Fig.} \mathrm{2),} \mathrm{it} \mathrm{is} \mathrm{found} \mathrm{above} \mathrm{the} \mathrm{pKa} \mathrm{of}$ PA at interfaces $(7.2-7.67,8)$ and therefore PA present in monolayers is mainly ionized. The waiting time for lipid spreading, solvent evaporation and for the film surface pressure to reach equilibrium could be as long as 200 minutes depending on the spreading volume and the initial surface pressure requested. all experiments were performed under red light to avoid FAP activation and PA consumption in monolayers.

\section{Analyses of FAP 3D structure.}

The 3D structures of FAPv1 (PDB ID: 5NCC (10)) and FAPv2 (PDB ID: 6YRU (36)) were visualized and views prepared using PyMOL (39). Electrostatic potential of FAPv2 protein chain was calculated with the pdb2pqr program v.2.1.1 (39). The dipolar moment was estimated and displayed using an inhouse written PyMOL plugin script applying a charge vector summation method similar to that of Felder et al. (40).

\section{Additional procedures.}

Supporting Information provides additional experimental details on (1.1) purification of thylakoid lipids from Chlorella, (1.2) solubilization of PA by $\beta-C D$ and BSA, (1.3) DLS measurements, (1.4) FAP activity assays using PA in micelles, and (1.5) Estimation of the surface exposed by LUVs and microemulsion and the related surface concentrations of palmitic acid.

\section{RESULTS AND DISCUSSION}

\section{Characterization of FAP substrate organization in water and lipid dispersions}

So far, the activity of FAP on FAs dispersed in water has been tested by adding FAs solubilized in $\operatorname{DMSO}(19)$ or ethanol(10) (what thereafter corresponds to "bulk" experiments). Since FAs have a very low solubility in water and self-aggregate in various forms $(30,41)$ (Figure 1), these procedures do not allow to control the presentation of substrate to the enzyme. To illustrate this point, we characterized dispersions of palmitic acid (PA) at 
various concentrations and at $\mathrm{pH} 9$ using visual inspection and dynamic light scattering (DLS) (Figure S1). PA has a low solubility in water of $7.2 \mathrm{mg} . \mathrm{L}^{-1}(280 \mu \mathrm{M})$ at $20^{\circ} \mathrm{C}$. With a pKa of 7.2-7.6 in organized systems $(42,43)$, it is mostly ionized at $\mathrm{pH}$ 9. When increasing the amounts of PA, the solutions evolved from a clear to cloudy, heterogeneous aspect with transient appearance of flat crystals above $300 \mu \mathrm{M}$. Particle size (zaverages) estimation by DLS ranged from approx. $\sim 1 \mu \mathrm{m}$ to $\sim$ $10 \mu \mathrm{m}$ (Figure S1). Although DLS is not the best technique for studying such heterogeneous systems with multimodal size distribution pattern and high polydispersity, it allowed a qualitative comparison of non-controlled PA dispersions with PA-containing liposomes (z-averages of 130 to $200 \mathrm{~nm}$; Figures $2 \mathrm{~F}, 3 \mathrm{~A}$ ), microemulsions (z-average of $\approx 270 \mathrm{~nm}$; Figure $4 \mathrm{~A}$ ) and mixed micelles (z-averages of 4 to $10 \mathrm{~nm}$ ). Interestingly, it was possible to produce stable egg phosphatidylcholine (PC) liposomes containing up to $45 \%$ (mol/mol) PA versus PC at $\mathrm{pH}$ 9 (Figure 3A), which confirmed previous studies showing that dipalmitoylphosphatidylcholine (DPPC) liposomes could accommodate up to $40 \mathrm{~mol} \%$ of PA before being disrupted with a lamellar to micellar phase transition(44).

\section{Role of the N-terminal $\alpha$-helix of FAP in its interactions with lipids}

The first recombinant CvFAP to be characterized(10) compassed residues 62-654 of the full-length CvFAP, i.e. without the 61 amino acid-long putative chloroplast transit peptide (Figure 2A and protein sequences in Supporting Information). This protein will be named 'FAPv1' thereafter. Its medium-resolution crystal structure shows a globular protein with a two-domain fold(10). The peptide stretch A62-S75 found at the N-terminal extremity of FAPv1 was however built as a 14 amino acid amphipatic $\alpha$-helix pointing out of the globular protein (Figures 2B and S2). Since this amphipatic $\alpha$-helix is located on the same side as the active site entrance, we hypothesized that it could play a role in lipid binding, as observed in retinol dehydrogenase(45), or in controlling enzyme activity like the propeptide in secretory phospholipases A2(46). A truncated variant of FAPv1 in which the $\mathrm{N}$-terminal extension was deleted (thereafter named 'FAPv2', compassing residues 76-654) was produced in E. coli and purified (see Supporting information). Its activity at various $\mathrm{pH}$ was compared to that of FAPv1 using PA as substrate, either randomly dispersed in bulk (Figure 2C) or added to large unilamellar vesicles (LUVs) made of egg PC (Figure 2D). These LUVs were stable at any $\mathrm{pH}$ tested and had an average size ranging from $210 \mathrm{~nm}$ at $\mathrm{pH} 6.5$ to $150 \mathrm{~nm}$ at $\mathrm{pH} 10$ as confirmed by DLS analysis (Figure $2 \mathrm{~F}$ and S3).

FAP activity was estimated from the conversion of PA into pentadecane. Both FAPv2 and FAPv1 had their optimum activity at $\mathrm{pH} 9$ on both type of substrates, but with higher activity on PA in LUVs $\left(0.64 \pm 0.03 \mu \mathrm{mol} . \mathrm{min}^{-1} . \mathrm{mg}^{-1}\right.$ for FAPv2 vs. $0.61 \pm 0.01 \mu$ mol. $\mathrm{min}^{-1} \cdot \mathrm{mg}^{-1}$. for FAPv1; Fig. 2D) than on PA in bulk $\left(0.39 \pm 0.03 \mu\right.$ mol. $\mathrm{min}^{-1} . \mathrm{mg}^{-1}$ for FAPv2 vs. $0.47 \pm$ $0.004 \mu$ mol. $\mathrm{min}^{-1} . \mathrm{mg}^{-1}$ for FAPv1; Figure 2C). It is however worth noting that the difference between FAPv2 and FAPv1 was more pronounced when their activities were measured with PA in LUVs (Figure 2D). Indeed, FAPv2 was 2- to 3.2-fold more active than FAPv1 in the $\mathrm{pH}$ range 6.5-8.5 ( $\mathrm{p} \leq 0.001$; Student's $\mathrm{t}$-test), covering most physiological $\mathrm{pH}$ values as well as the $\mathrm{pK}_{\mathrm{a}}$ of PA, and 1.4-fold more active than FAPv1 at pH 10 ( $\mathrm{p} \leq 0.001$; Figure 2E). At $\mathrm{pH} 9$, the difference between FAPv2 and FAPv1 was not significant $(\mathrm{p}>0.1)$. When FAP activity was measured with PA in bulk, the difference between FAPv2 and FAPv1 was not significant at any $\mathrm{pH}(\mathrm{p}>0.01)$.

A
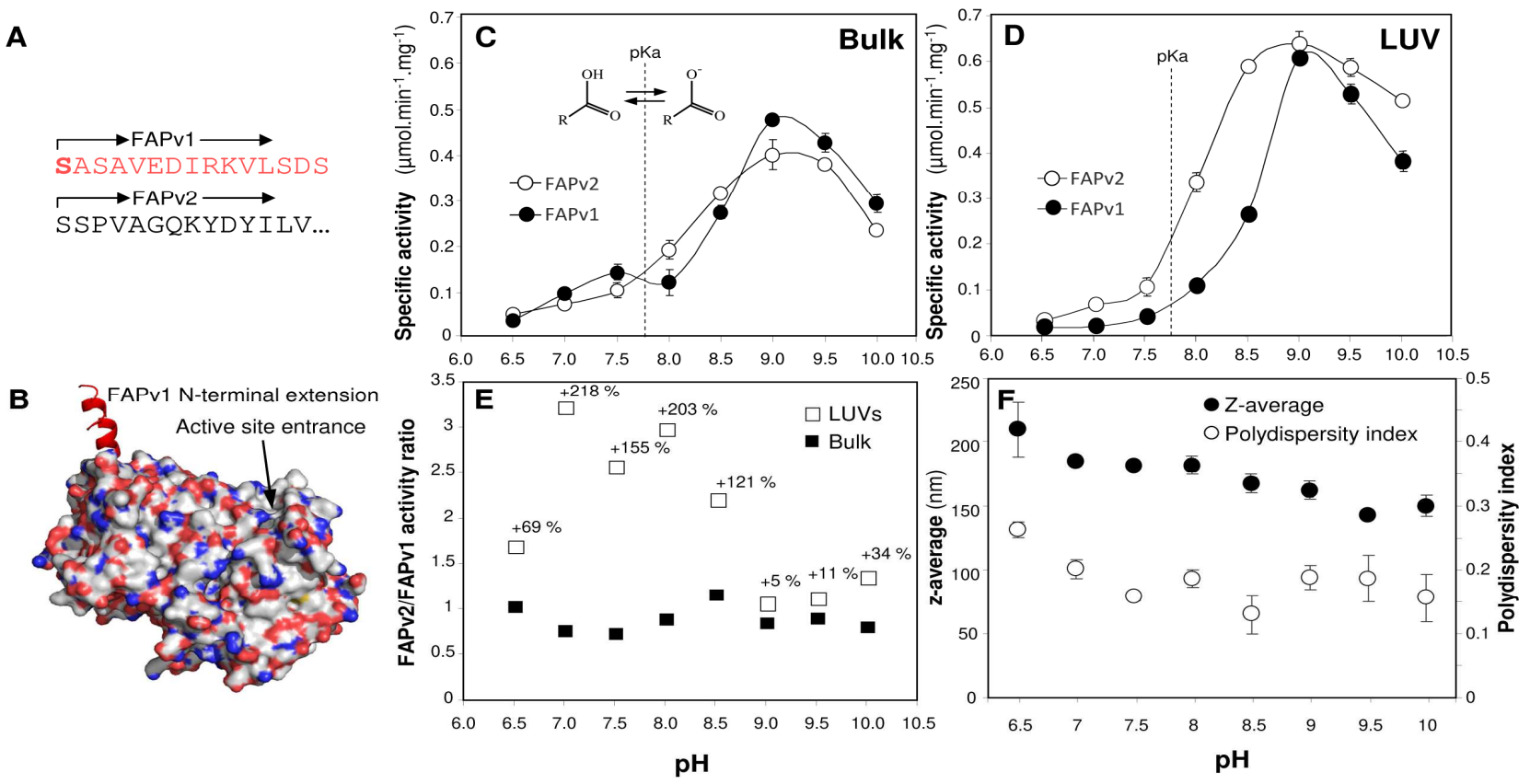

Figure 2. Comparison of the specific activities of the recombinant FAPv1 and FAPv2 variants. (A) N-terminal sequences of FAPv1 and FAPv2. The N-terminal extension present in FAPv1 and deleted in FAPv2 is indicated in red letters. Note that residue 61 in CvFAP (R) is substituted by $\mathrm{S}$ in FAPv1 (bold red letter) due to construct for cleavage by TeV protease. (B) 3D structure of FAPv1 showing the N- 
terminal extension pointing out of the globular domain as an $\alpha$-helix (see also Figure S2). (C, D) Variations with $\mathrm{pH}$ in the specific activities of FAPv1 and FAPv2 on PA dispersed in bulk or incorporated into egg PC large unilamellar vesicles (LUV), respectively. The molar fraction of PA in LUVs was $22 \mathrm{~mol} \%$. FAP activity assays were all performed using an enzyme concentration of around $100 \mathrm{nM}$ under LED white light at an intensity of $2000 \mu \mathrm{mol}$ photon.m-1. $\mathrm{s}^{-1}$ and at $20^{\circ} \mathrm{C}$ for $15 \mathrm{~min}$. FAPv1 and FAPv2 specific activities were estimated from the conversion of PA into pentadecane, quantified by GC-MS/FID, and were expressed in $\mu \mathrm{mol} \cdot \mathrm{min}^{-1} \cdot \mathrm{mg}^{-1}$. The dotted line indicates the pKa of long chain FAs (7.6(42)). (E) Variations with pH in FAPv2 to FAPv1 activity ratio. (F) Variation with pH in the Zaverage and polydispersity index of PA-containing LUVs prepared with egg PC for the enzymatic assays of FAP. All values are mean \pm $\mathrm{SD}(\mathrm{n}=3)$. PA concentration was $1000 \mu \mathrm{M}$ in all experiments while PC concentration in LUV dispersion was $3600 \mu \mathrm{M}$.

Using egg PC monomolecular films as model membranes, we then compared the adsorption properties of FAPv1 and FAPv2, in the absence and presence of PA. Adsorption kinetics were recorded with increasing concentrations of FAP (6.7 to 33.5 $\mathrm{nM}$ ) injected below the lipid films spread at the air-water interface, at an initial surface pressure of $10 \mathrm{mN} \cdot \mathrm{m}^{-1}$ (Figure S4). Adsorption $\left(\mathrm{k}_{\mathrm{a}}, \mathrm{M}^{-1} \mathrm{~s}^{-1}\right)$, desorption $\left(\mathrm{k}_{\mathrm{d}}, \mathrm{s}^{-1}\right)$ and dissociation $\left(\mathrm{K}_{\mathrm{D}}\right.$, $\mathrm{M})$ rate constants were estimated from changes in surface pressure with time measured with a Langmuir film balance and fitting of adsorption curves to Langmuir adsorption isotherm, as previously described for lipases(37). We found a higher binding of FAPv2 to PC $\left(K_{D}=7.23 \mathrm{nM}\right)$ compared to FAPv1 $\left(K_{D}=8.28\right.$ $\mathrm{nM})$ and the difference in affinity was increased in the presence of PA (6.52 nM for FAPv2 vs. $9.78 \mathrm{nM}$ for FAPv1; Table 1).

Table 1: Kinetic constants of FAP adsorption onto lipid monolayers. Values are mean $\pm \mathrm{SD}(\mathrm{n}=3)$.

\begin{tabular}{|c|c|c|c|c|c|}
\hline Enzyme & Lipids & $\begin{array}{c}\Pi_{\mathrm{c}} \\
\left(\mathrm{mN} \mathrm{m}^{-1}\right)\end{array}$ & $\begin{array}{l}\mathrm{k}_{\mathrm{a}} \times 10^{-4} \\
\left(\mathrm{M}^{-1} \mathrm{~s}^{-1}\right)\end{array}$ & $\begin{array}{c}\mathrm{k}_{\mathrm{d}} \times 10^{-4} \\
\left(\mathrm{~s}^{-1}\right)\end{array}$ & $\begin{array}{c}\mathrm{K}_{\mathrm{D}} \\
(\mathrm{nM})\end{array}$ \\
\hline \multirow{2}{*}{ FAPv1 } & \multicolumn{2}{|l|}{ PC } & $\begin{array}{l}2.88 \\
\pm 0.58\end{array}$ & $\begin{array}{l}2.38 \\
\pm 1.26\end{array}$ & $\begin{array}{l}8.28 \\
\pm 0.71\end{array}$ \\
\hline & \multicolumn{2}{|l|}{$\mathrm{PC}+\mathrm{PA}$} & $\begin{array}{l}3.13 \\
\pm 0.48\end{array}$ & $\begin{array}{l}3.07 \\
\pm 1.06\end{array}$ & $\begin{array}{l}9.78 \\
\pm 0.54\end{array}$ \\
\hline \multirow{8}{*}{ FAPv2 } & $\mathrm{PC}$ & 24.18 & $\begin{array}{l}3.03 \\
\pm 0.23\end{array}$ & $\begin{array}{l}2.19 \\
\pm 0.46\end{array}$ & $\begin{array}{l}7.23 \\
\pm 0.21\end{array}$ \\
\hline & $\mathrm{PC}+\mathrm{PA}$ & 24.42 & $\begin{array}{l}3.76 \\
\pm 0.31\end{array}$ & $\begin{array}{l}2.45 \\
\pm 0.36\end{array}$ & $\begin{array}{l}6.52 \\
\pm 0.15\end{array}$ \\
\hline & DGDG & 23.75 & $\begin{array}{l}3.28 \\
\pm 0.26\end{array}$ & $\begin{array}{l}2.29 \\
\pm 0.31\end{array}$ & $\begin{array}{l}6.99 \\
\pm 0.13\end{array}$ \\
\hline & $\mathrm{DGDG}+\mathrm{PA}$ & 24.92 & $\begin{array}{l}3.25 \\
\pm 0.53\end{array}$ & $\begin{array}{l}1.54 \\
\pm 0.13\end{array}$ & $\begin{array}{l}4.72 \\
\pm 0.47\end{array}$ \\
\hline & \multicolumn{2}{|c|}{$\mathrm{PC}+\mathrm{PA} / \mathrm{PC}$ ratio } & 1.24 & 1.12 & 0.90 \\
\hline & \multicolumn{2}{|c|}{ DGDG+PA/DGDG ratio } & 0.99 & 0.67 & 0.68 \\
\hline & \multicolumn{2}{|c|}{ DGDG/PC ratio } & 1.08 & 1.05 & 0.97 \\
\hline & \multicolumn{2}{|c|}{$\begin{array}{l}\mathrm{DGDG}+\mathrm{PA} / \mathrm{PC} \\
\text { ratio }\end{array}$} & 0.86 & 0.63 & 0.72 \\
\hline
\end{tabular}

In summary, the presence of the N-terminal amphipatic A62S75 peptide in FAPv1 is shown here to reduce both the binding of FAP at the lipid-water interface and the activity of FAP on PA embedded in a well-defined lipid-water interface such as LUVs. In this regard, the N-terminal peptide of FAP has a contribution similar to that of propeptides in some secretory phospholipases A2(46). Since the FAPv2 truncated form is also the best characterized FAP variant in terms of photocatalytic mechanism and structure(36)., we decided to use
FAPv2 for studying enzyme activity at various lipid-water interfaces.

\section{FAPv2 activity on PA-containing LUVs}

Since FAP displayed a higher activity on PA entrapped inside the phospholipid bilayer of LUV, we investigated the capacity of LUVs to incorporate various amounts of FAs. Egg PC LUVs containing up to $50 \%(\mathrm{~mol} / \mathrm{mol}) \mathrm{PA}$ versus $\mathrm{PC}$ were prepared and characterized by DLS analysis (Figure 3A and S5). Activities of FAPv2 on vesicular dispersions of PA and PA directly dispersed in bulk at the same overall concentrations were compared (Figure 3B). With PA-enriched LUVs, FAPv2 specific activity clearly increased with PA concentration and raised from $0.51 \pm 0.05 \mu \mathrm{mol} . \mathrm{min}^{-1} . \mathrm{mg}^{-1}$ at $800 \mu \mathrm{M}$ PA to $1.04 \pm$ $0.06 \mu$ mol. $\mathrm{min}^{-1} \cdot \mathrm{mg}^{-1}$ at $3000 \mu \mathrm{M}$ PA, while the activity on PA dispersed in bulk remained close to $0.4 \mu \mathrm{mol} \cdot \mathrm{min}^{-1} \cdot \mathrm{mg}^{-1}$ regardless of PA concentration. Increasing the apparent PA concentration without controlling its organization in water thus had no effect on enzyme activity, suggesting that PA alone selforganized in assemblies with only a fraction of PA accessible to FAP, or with a restricted diffusion of PA.

Since FAP appeared to be active on PA at the surface of LUVs, we also expressed its activity as a function of the surface concentration of PA $\left(\mu \mathrm{mol} . \mathrm{m}^{-2}\right)$, estimated from the total surface of LUVs $\left(0.72\right.$ to $\left.0.9 \mathrm{~m}^{2}\right)$, the bulk concentrations of PA and egg $\mathrm{PC}$, and their respective molecular areas (see Supporting Information for calculations). The specific activity of FAPv2 on PA in LUVs doubled when the surface concentration of PA was increased by a factor 2.98 (versus 3.75 for the volumetric concentration). The specific activity of FAPv2 thus appeared to be correlated to the surface concentration of PA in this wellcontrolled organized system (Figure 5). It is worth noting that when the molar fraction of PA versus PC exceeded $45 \%$ $\mathrm{mol} / \mathrm{mol}$ beyond $3000 \mu \mathrm{M}$ PA, FAPv2 specific activity started declining (Figure 3B), while the DLS signal indicated LUV instability. It could possibly result from a lamellar to micellar phase transition induced by PA (Figure 3A)(44). 

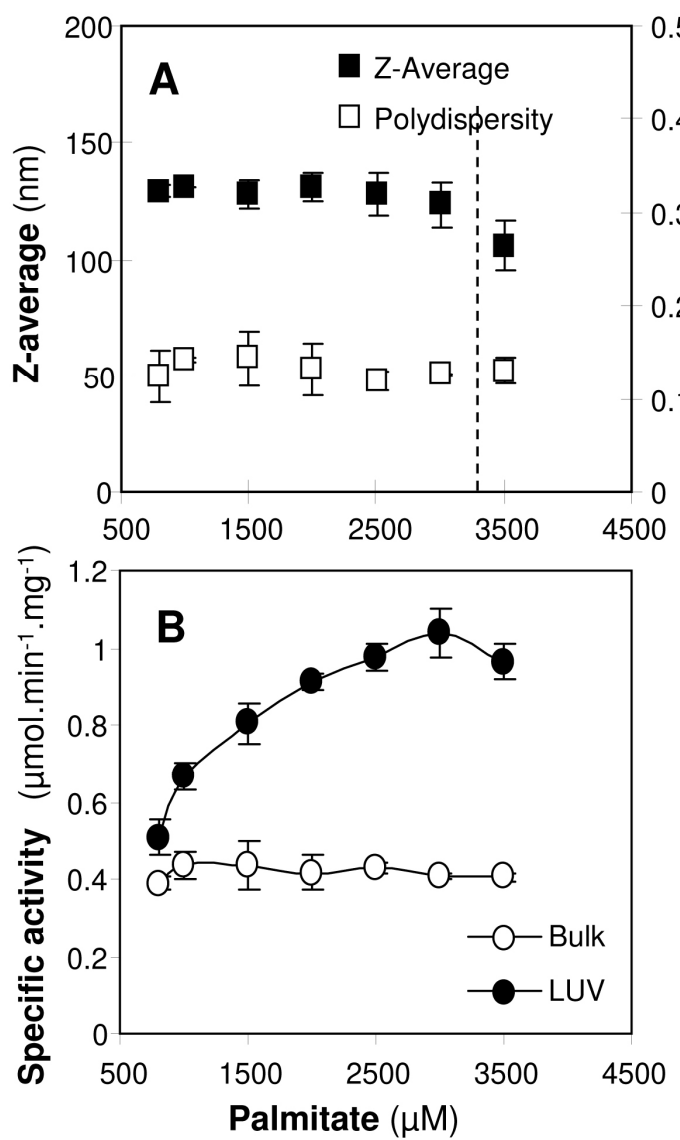

Figure 3. FAPv2 activity on fatty acid incorporated in phospholipid liposomes. (A) Measurement by DLS of z-average and polydispersity index of palmitate-enriched LUVs prepared with egg PC for the enzymatic assays of FAPv2 at $\mathrm{pH} 9$. The dotted line indicates the palmitate concentration above which liposomes became unstable and were disrupted. (B) Variations with PA concentration of FAPv2 specific activity on PA substrate dispersed in bulk or incorporated into egg PC LUVs. All assays were performed at $\mathrm{pH} \mathrm{9,} \mathrm{i.e.} \mathrm{a} \mathrm{pH}$ value above the apparent $\mathrm{pKa}$ of palmitic acid in a phosphatidylcholine bilayer (7.2(42)) and the reaction volume was $500 \mu \mathrm{L}$. The overall bulk concentration of PA ranged from 800 to $3500 \mu \mathrm{M}$ while in experiments with LUVs, the egg PC concentration was kept constant at $3600 \mu \mathrm{M}$. FAPv2 specific activity is expressed in $\mu$ mol. $\mathrm{min}^{-1} \cdot \mathrm{mg}^{-1}$. Values are mean \pm SD $(n=3)$. N.B.: Compared to Figure 2F, LUVs were prepared with an improved protocol including alternate steps of snap-freezing and heating, as well as five additional extrusion cycles, which led to a lower Z-average.

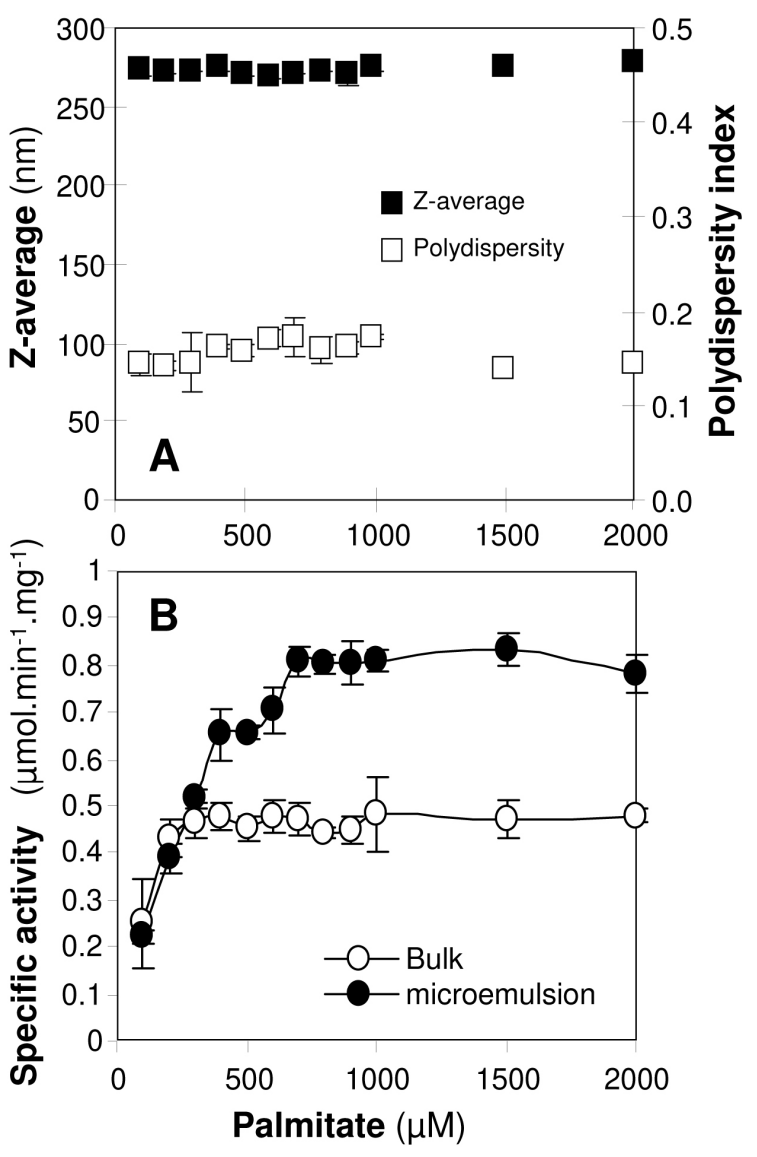

Figure 4. Effects of fatty acid incorporation in phospholipidstabilized soybean oil microemulsion on FAPv2 activity. (A) Measurement by DLS of Z-average and polydispersity index of the microemulsions prepared for the assay of FAPv2. (B) FAPv2 specific activity as a function of the concentration of PA either dispersed in bulk or incorporated into the microemulsion. The reaction volume was $500 \mu \mathrm{L}$ and the $\mathrm{pH}$ was 9 . The overall bulk concentration of PA ranged from 100 to $2000 \mu \mathrm{M}$. The microemulsion was prepared using a twenty-fold dilution of Intralipid $^{\circledR} 20 \%$ which resulted in TAG (soybean oil) and phospholipid (egg PC) amounts of $1 \%(w / w)$ and $0.06 \%(w / w)$, respectively. The egg PC concentration was $780 \mu \mathrm{M}$. FAPv2 concentration was $100 \mathrm{nM}$ and its specific activity was expressed in $\mu$ mol. $\mathrm{min}^{-1} \cdot \mathrm{mg}^{-1}$. Values are mean \pm SD $(\mathrm{n}=5)$. 


\section{FAPv2 activity on PA incorporated in a microemulsion}

Intralipid ${ }^{2} 20 \%$ (a microemulsion made with purified soybean oil $(20 \% \mathrm{w} / \mathrm{v})$ and stabilized by egg PC) was chosen as another type of well-defined interface to display PA. Intralipid ${ }^{\circledR} 20 \%$ was diluted 20 -fold in the reaction buffer in order to reduce opacity of the reaction medium for the light-dependent FAP assays and PA was further added to final concentrations ranging from 100 to $2000 \mu \mathrm{M}$ without inducing the coalescence of microemulsion droplets. DLS analysis of the resulting $1 \% \mathrm{w} / \mathrm{v}$ microemulsions containing PA revealed that they all had a $\mathrm{z}-$ average close to $270 \mathrm{~nm}$ with a monomodal size distribution and low polydispersity index below 0.2 (Figure 4A, S6). The size of the microemulsion droplets thus remained close to that of Intralipid® $20 \%$ at neutral $\mathrm{pH}(250 \pm 40 \mathrm{~nm}(47))$ and was not changed by dilution and addition of $\mathrm{PA}$, as well as by $\mathrm{pH}$ variations from 6.5 to 10 (Figure S7). The final $1 \% \mathrm{w} / \mathrm{v}$ Intralipid ${ }^{\circledR}$ emulsion all contained egg $\mathrm{PC}$ at a concentration of $780 \mu \mathrm{M}$, with PC molecules assumed to form a monolayer at the oil-water interface in which PA molecules were embedded (Figure 1B).

FAP activity on PA-containing microemulsions at $\mathrm{pH} 9$ increased steadily with PA concentration, from $0.2 \mu$ mol.min ${ }^{1} . \mathrm{mg}^{-1}$ at $100 \mu \mathrm{M}$ PA to $0.8 \mu \mathrm{mol} \cdot \mathrm{min}^{-1} \cdot \mathrm{mg}^{-1}$ at $700 \mu \mathrm{M}$ PA, before reaching a plateau (Figure 4B). In comparison, FAP activity on PA in bulk was around 2-fold lower with a plateau at $0.47 \mu \mathrm{mol} \cdot \mathrm{min}^{-1} \cdot \mathrm{mg}^{-1}$ at $200 \mu \mathrm{M}$ PA. These data indicated that the use of PA-containing microemulsions is an effective way to present the PA substrate to FAP. The hydrophobic core of the microemulsion might also favor the reaction as an acceptor of the hydrocarbon products, with FAP acting like a phase transfer catalyst.

FAPv2 activity on PA in LUVs and microemulsions is correlated to substrate surface concentration

Similar to our approach with LUVs, we estimated the concentration of PA at the surface of the microemulsion $\left(\mu \mathrm{mol} . \mathrm{m}^{-2}\right)$ based on the surface and number of microemulsion droplets deduced from the hydrodynamic diameter measured by DLS and the volumetric concentrations of PA, assuming that all PA molecules were present at the oil-water interface (see Supporting Information for calculations). The specific activity of FAPv2 as a function of PA surface concentration appeared to be lower in microemulsion than in LUVs (Figure 5). In both cases, however, the variation in FAPv2 activity showed a hyperbolic saturation profile (Figure 5). Assuming a pseudoMichaelis-Menten model based on surface and not volume concentrations of substrate(48), the kinetic parameters of the enzyme reaction (Table 2) were estimated by non-linear regression. The determination of $\mathrm{K}_{\mathrm{m}}^{*}$ expressed in $\mu \mathrm{mol} . \mathrm{m}^{-2}$ allowed to quantify the higher affinity of FAPv2 for PA in LUV $\left(\mathrm{K}_{\mathrm{m}}^{*}=0.98\right)$ than for PA in microemulsion $\left(\mathrm{K}_{\mathrm{m}}^{*}=1.32\right)$. The molecular turnover $\left(\mathrm{k}_{\mathrm{cat}}\right)$ of PA decarboxylation by FAPv2 was also higher in $\operatorname{LUV}\left(1.64 \mathrm{~s}^{-1}\right)$ than in microemulsion $\left(1.08 \mathrm{~s}^{-1}\right)$.

\section{Assay of FAPv2 activity on mixed micelles containing PA}

Since FAPv2 appeared to be active on PA present in at least two different types of interfaces, we further investigated whether a micellar presentation of PA could provide a suitable substrate for FAP. Mixed micelles were prepared using various concentrations of two common surfactants: a negatively charged bile salt (sodium taurodeoxycholate; NaTDC) and a neutral detergent (Triton X-100). PA concentration was kept constant (1 $\mathrm{mM}$ ) while surfactant to PA molar ratio was increased from 0 to 16. The micellar solubilization of PA was followed by DLS analysis. Particle size distributions shifted from large particles with a multimodal distribution and a main population close to 1 $\mu \mathrm{m}$ when PA was dispersed alone in solution (Figure S8) to small micellar aggregates with main particle size populations of around 4-5 nm and 7-11 $\mathrm{nm}$ in the presence of NaTDC (Figure 6A and S8) and Triton X-100 (Figure 6B and S8), respectively. Furthermore, it could be deduced from the intensity of the DLS signal that most compounds dispersed in the aqueous phase were gradually transferred into micelles when increasing the surfactant concentration (Figure 6A and 6B; from $10 \%$ at $2 \mathrm{mM}$ NaTDC to $88 \%$ at $16 \mathrm{mM}$ ). FAPv2 activity on PA was found to decrease with increasing surfactant concentration, reaching a relative activity below $25 \%$ at the highest concentration of surfactant tested (Figure 6C). FAPv2 activity therefore decreased with the incorporation of PA into micelles. Moreover, Triton X-100 has a lower critical micellar concentration $(0.23$ $\mathrm{mM})$ than NaTDC (4 mM) and it decreased FAPv2 activity at lower concentrations compared to NaTDC. Thus, the micellar solubilization of PA by surfactants is not suitable for improving FAP activity on fatty acids dispersed in water.

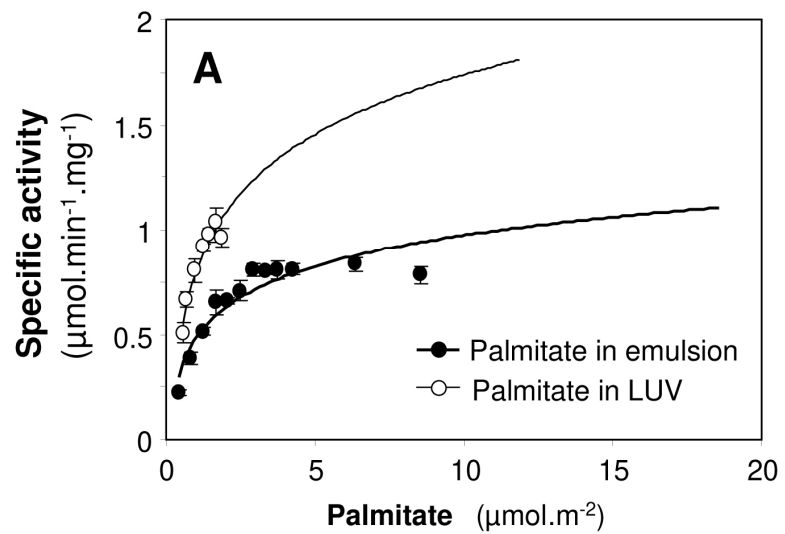

Figure 5. Variation in FAPv2 specific activity $\left(\mu \mathrm{mol} \cdot \mathrm{min}^{-1} \cdot \mathrm{mg}^{-1}\right)$ as a function of palmitate surface concentration $\left(\mu \mathrm{mol} . \mathrm{m}^{-2}\right)$ in LUV and at the surface of phospholipid-stabilized soybean oil microemulsion. The surface concentrations of PA were estimated as described in Supporting Information. Values are mean \pm SD $(n=3)$.

Table 2: Kinetic parameters of FAPv2 activity on PA at interfaces, estimated by non-linear regression and fitting of the data shown in Figure 5 to Michaelis-Menten equation using the software program GraphPad Prism.

\begin{tabular}{cccc}
\hline PA presentation & $\begin{array}{c}\mathrm{V}_{\max } \\
\left(\mu \operatorname{mol} . m_{i n}^{-}\right. \\
\left.{ }^{1} \mathrm{mg}^{-1}\right)\end{array}$ & $\begin{array}{c}\mathrm{K}_{\mathrm{m}}^{*} \\
\left(\mu \mathrm{mol} . \mathrm{m}^{-2}\right)\end{array}$ & $\begin{array}{c}\mathrm{k}_{\mathrm{cat}} \\
\left(\mathrm{s}^{-1}\right)\end{array}$ \\
\hline Microemulsion & $1.06 \pm 0.05$ & $1.32 \pm 0.19$ & $1.08 \pm 0.06$ \\
& $(\mathrm{p}=0.0004)$ & $(\mathrm{p}=0.0004)$ & \\
LUV & $1.61 \pm 0.2$ & $0.98 \pm 0.27$ & $1.64 \pm 0.2$ \\
& $(\mathrm{p}=0.0004)$ & $(\mathrm{p}=0.01)$ & \\
\hline
\end{tabular}




\section{Assay of FAPv2 activity on PA bound to $\beta$-cyclodextrin and BSA}

We also tested the use of $\beta$-cyclodextrin $(\beta-C D)$ or bovine serum albumin (BSA) as alternative ways of PA solubilization in water. Changes in the particle size distribution of the PA dispersion in water were monitored by DLS and indicated a gradual solubilization of PA by $\beta-\mathrm{CD}$ (Figure S9). The complexation of PA by $\beta-C D$ had a negative effect on FAPv2 activity, that decreased by half at a 5-fold molar excess of $\beta$-CD over PA (Figure S10). Similar results were obtained using fatty acid-free BSA, but FAPv2 activity was already reduced by half using a BSA to PA molar ratio of 0.5 (Figure S10). This was probably due to the binding of several fatty acid molecules to BSA.

\section{Adsorption of FAPv2 onto monomolecular films of PC and galactolipids}

Since FAPv2 showed a preference for PA embedded in lipid bilayers (LUV) and at the surface of a microemulsion, we further tested its ability to bind to model membranes consisting of monomolecular lipid films spread at the air-water interface and whose surface pressure was measured using a Langmuir film balance (Figure 7A). Since Chlorella variabilis FAP is in vivo a chloroplast-localized enzyme able to partly associate to the thylakoid membrane fraction(49), FAPv2 adsorption was first tested on a monolayer of total thylakoid lipids isolated from this microalgae. FAPv2 was indeed found to adsorb onto thylakoid lipids (Figure 7B). Adsorption of FAPv2 was then tested on films of egg PC or di-galactosyl-di-dodecanoylglycerol (C12-DGDG), in the absence and presence of PA. C12DGDG is a synthetic galactolipid forming stable monolayers that can be used as a model of thylakoid galactolipids(35). The adsorption on PC and PC + PA occurred with a lag phase of approximately 15-20 minutes, while the enzyme readily adsorbed onto C12-DGDG, C12-DGDG + PA and thylakoid lipids upon its injection into the aqueous phase. The maximum surface pressures reached at equilibrium were similar and close to $24 \mathrm{mN} . \mathrm{m}^{-1}$, regardless of the lipid film. To estimate adsorption $\left(\mathrm{k}_{\mathrm{a}}, \mathrm{M}^{-1} \mathrm{~s}^{-1}\right)$, desorption $\left(\mathrm{k}_{\mathrm{d}}, \mathrm{s}^{-1}\right)$ and dissociation $\left(\mathrm{K}_{\mathrm{D}}\right.$, $\mathrm{M})$ rate constants (Table 1), FAPv2 adsorption kinetics were recorded with increasing concentrations of enzyme (2.2 to 33.5 $\mathrm{nM}$ ) injected below the films at an initial surface pressure of 10 $\mathrm{mN} . \mathrm{m}^{-1}$ and adsorption curves (Figure S11) were fitted to Langmuir adsorption isotherm as previously described for lipases(37). We found similar dissociation constants for FAPv2 binding to PC (7.23 nM) and C12-DGDG (6.99 nM), and in both cases, the addition of PA to the monolayer lowered the $\mathrm{K}_{\mathrm{D}}$ to $6.52 \mathrm{nM}$ and $4.72 \mathrm{nM}$ for FAPv2 binding onto PC and C12DGDG, respectively. The presence of PA therefore favored FAPv2 binding to both phospholipid and galactolipid monolayers.

The critical surface pressures of FAPv2 penetration into these monolayers (e.g. the surface pressure above which the injection of the protein below the film does not induce a change in surface pressure anymore; $\Pi_{c}, \mathrm{mN}_{\mathrm{m}} \mathrm{m}^{-1}$; Table 1) were deduced from the plot of maximum surface pressure increase with the initial surface pressure of the monolayer under which the enzyme (33.5 nM) was injected (Figure 7B and C). 

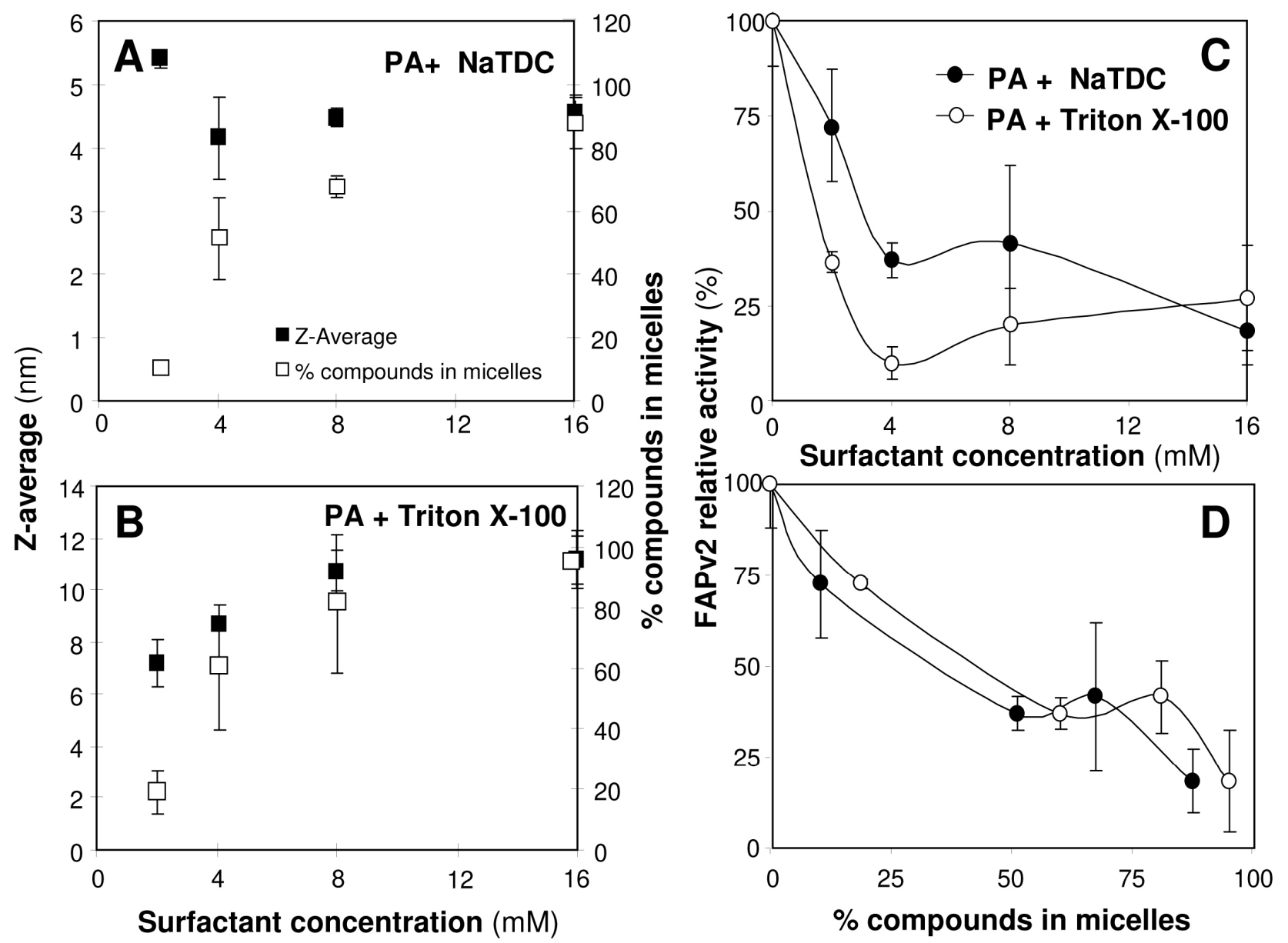

Figure 6. Effects of surfactants on fatty acid incorporation into mixed micelles and FAPv2 activity. Various concentrations of NaTDC or Triton X-100 ranging from 0 to $16 \mathrm{mM}$ were tested while PA concentration was kept at $1 \mathrm{mM}$. Panels A, B: Particle size (Z-average) of mixed NaTDC-PA (A) and Triton X-100-PA (B) micelles and amounts of compounds present in mixed micelles based on DLS measurements and intensity. Panel C: variations in FAPv2 relative activity on PA (\% of maximum activity in the absence of surfactants) as a function of surfactant concentration at $\mathrm{pH} 9$ and $20^{\circ} \mathrm{C}$. Panel D: variations in FAPv2 relative activity on PA with formation of micelles. FAPv2 activity was deduced from residual PA present in micelles at the end of the reaction because recovery of hydrocarbons from micelles was not reliable (see Materials and Methods section). The critical micellar concentrations of NaTDC and Triton X-100 are 4 mM and $0.23 \mathrm{mM}$, respectively.

All $\Pi_{c}$ values were close to $24 \mathrm{mN} \cdot \mathrm{m}^{-1}$, which indicates a high capacity of penetration into a monolayer of polar lipids. This result suggests that FAP can bind to biological membranes, the lateral pressure of which is close to $30 \mathrm{mN} \cdot \mathrm{m}^{-1}$ (50). It is worth recalling that $\Pi_{c}$ has been used to rank lipolytic enzymes for their capacity to bind to, and even disrupt, biological membranes. Phospholipases with $\Pi_{\mathrm{c}}>31 \mathrm{mN} \cdot \mathrm{m}^{-1}$ have hemolytic activities(51), while some of the most tensioactive lipases, able to hydrolyze oil droplets covered by a phospholipid layer, have $\Pi_{c}$ of $21.3 \mathrm{mN} . \mathrm{m}^{-1}$ (dog gastric lipase) (52), 24 $\mathrm{mN} . \mathrm{m}^{-1}$ (human gastric lipase) (53) and $31.8 \mathrm{mN} . \mathrm{m}^{-1}$ (Yarrowia lipolytica LIP2 lipase) (52).
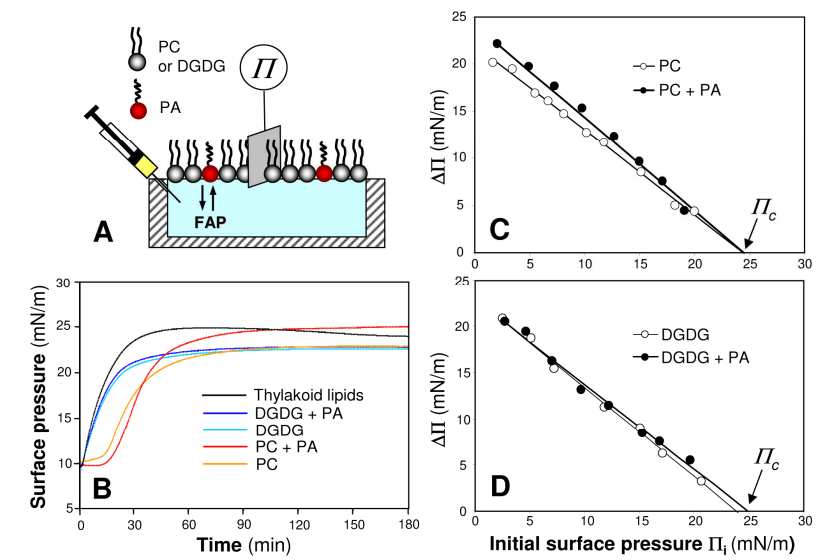

Figure 7. Adsorption of FAPv2 onto monomolecular films of lipids 
spread at the air-water interface and effects of PA addition to the films. A) Schematic representation of FAPv2 injection below the film and measurement of changes in surface pressure $\left(\Pi, \mathrm{mN} \cdot \mathrm{m}^{-1}\right)$ using a Wilhelmy blade connected to a microbalance. B) Variation in surface pressure with time after injection of FAPv2 below monolayers of lipids extracted from Chlorella variabilis thylakoids, egg PC, egg PC $(64.3 \% \mathrm{~mol} / \mathrm{mol})+\mathrm{PA}(35.7 \% \mathrm{~mol} / \mathrm{mol}), \mathrm{C} 12-$ DGDG and C12-DGDG $(64.3 \% \mathrm{~mol} / \mathrm{mol})+\mathrm{PA}(35.7 \% \mathrm{~mol} / \mathrm{mol})$. The adsorption kinetics shown here were recorded after injecting FAPv2 (33.5 nM final protein concentration) below the films at an initial surface pressure of $10 \mathrm{mN} . \mathrm{m}^{-1}$. (C) Variation in maximum surface pressure increase $\left(\Delta \Pi_{\max }\right)$ with the initial surface pressure $\left(\Pi_{\mathrm{i}}\right)$ upon adsorption of FAPv2 onto egg PC \pm PA monolayers. (D) Variation in $\Delta \Pi_{\max }$ with $\Pi_{\mathrm{i}}$ upon adsorption of FAPv2 onto C12DGDG \pm PA monolayers. The critical surface pressure of penetration $\left(\Pi_{c}\right)$ was estimated from linear regression and its intercept with the $\Pi_{\mathrm{i}}$-axis. Experiments were performed under red light in order to prevent the degradation by FAPv2 of monolayers containing PA.

\section{Identification of an Interfacial Recognition Site on FAP}

Since FAP preferentially acts on PA embedded in large lipid assemblies, a deeper analysis of the novel 3D structure of FAPv2(36) (PDB: 6YRU) was undertaken to identify a lipid binding or an interfacial recognition site (IRS). Since hydrophobic interactions are a main driving force in proteinlipid interactions, we first looked at hydrophobic amino acids at the surface of FAP and identified several clusters located on the same side as the active site entrance, from which a cocrystallized C18 fatty molecule is emerging (Figure 8). Several residues (I416, A417, Y419, L420, L421) belong to the amphiphilic $\alpha$-helix 13 bordering the active site entrance and are part of a larger cluster in interaction with the fatty acid alkyl chain (I126, I411, I416, L420, Y419, L425). Hydrophobic residues (P78, V79, A80) from FAPv2 N-terminal end are also exposed on the same side (Figure 8) together with many basic amino acids (R109, R122, K125, R132, R161, R221, K270, R278, R287, R288, K408, K413, K414, R424, K471, K501) and only five acidic amino acids (D118, D123, D320, E325, E407) (Fig. 8B and D). The accessible hydrophobic surface exposed on this plateau (1663 $\left.\AA^{2}\right)$ is comparable to IRS in lipases(54), while the surface exposed by the surrounding basic residues $\left(2068 \AA^{2}\right)$ is reminiscent of IRS, or i-face, in secretory phospholipases A2, these latter having a preference for negatively charged phospholipids(55). Interestingly, the dipolar moment vector of FAPv2 (estimated to be 1527 Debye and represented by an arrow in Figure $8 \mathrm{~B}$ ) is projected through the plateau with its positive pole located exactly above the entry of the active site. Thus, this plateau could be the IRS of FAP, involved in the interaction of FAP with ionized fatty acids and negatively charged interfaces like chloroplast membranes(56), where FAP is partly located(49). From the IRS location on one side of FAP and the direction of the dipolar moment vector, one can predict the possible orientation of FAP bound to membranes.

\section{CONCLUSION}

We have shown that FAP displays its highest activity on ionized FAs present in organized lipid assemblies like LUVs and microemulsions (Figure 2, 3 and 4). FAP activity was found to vary with FA concentration when FA were incorporated in LUVs or microemulsions, while it was not the case with FA randomly dispersed in bulk (Figures 3 and 4). These welldefined systems also allowed showing the dependency of FAP activity on FA surface concentration (Figure 5), with the 1 estimation of pseudo-Michaelis-Menten constants $\left(\mathrm{K}_{\mathrm{M}}{ }^{*}\right)$, expressed in $\mu \mathrm{mol} . \mathrm{m}^{-2}$, and interfacial turnovers $\left(\mathrm{k}_{\mathrm{cat}} * ; \mathrm{s}^{-1}\right)$ (Table 2). Since (i) FAP is a water-soluble enzyme acting on water-insoluble substrates (long chain FAs) present at organized lipid-water interfaces, and (ii) the velocity of the enzyme reaction depends on the two-dimensional surface concentration of FAs at these interfaces, FAP can be defined as an interfacial enzyme. This definition is not exclusive of some activity on water-soluble substrates as also observed with lipases but the availability of these substrates to FAP is unlikely in its natural context.

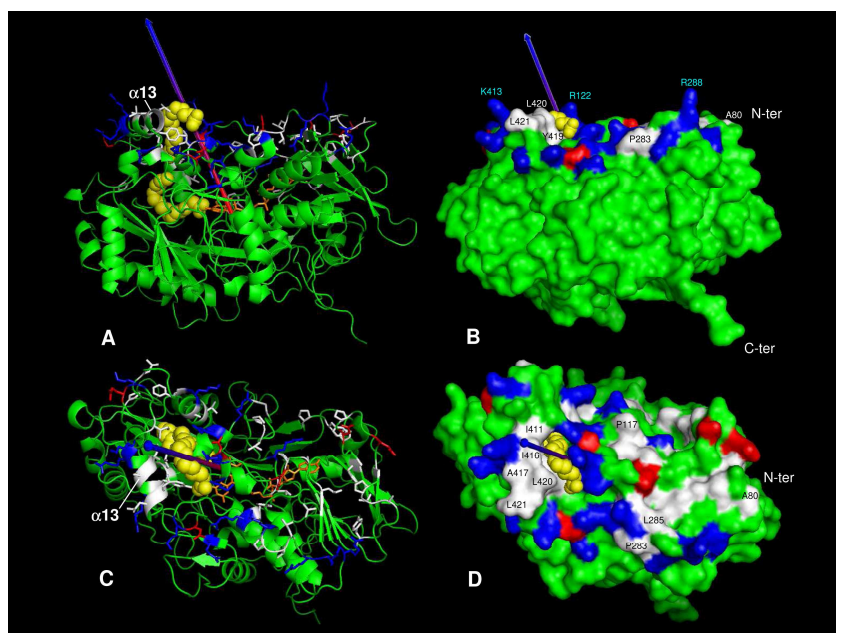

Figure 8. Interfacial Recognition Site and dipolar moment in FAPv2. Side (A, B) and top (C, D) views of FAPv2 are shown either as ribbon model with secondary structure elements (A, C) or molecular surface representation (B,D). Top views are aligned on a plateau found on one side of FAPv2, from which one cocrystallized $\mathrm{C} 18$ fatty acid molecule (shown as yellow spheres) emerges from the enzyme active site entrance and interacts with several residues from the amphipathic helix $\alpha 13$. A second fatty acid molecule is found deeper within the active site. All atoms of FAPv2 are colored in green, except those belonging to hydrophobic (white), basic (blue) and acidic (red) amino acids found in the plateau. The arrow originating from the center of gravity of the protein shows the orientation of the dipolar moment (1527 Debye) estimated for FAPv2 using a Pymol script based on an approach similar to Felder et al. (40). The blue extremity indicates the positive pole. The structure of FAPv2 is deposited in the Protein Databank under the accession number 6YRU(36).

Moreover, the micellar solubilization of FAs by surfactants (NaTDC and Triton X-100; Figure 6) or their complexation by $\beta$-CD or BSA (Figure S9) impairs FAP activity, suggesting that the enzyme cannot access FAs in this form and presents some selectivity for organized interfaces exposed by liposomes or microemulsions.

Experiments with monomolecular films of phospholipids and galactolipids revealed a high affinity of FAP to these model interfaces, which was increased in the presence of FAs (Figure 7). These experiments allowed estimating adsorption and desorption rate constants for FAP (Table 1). Altogether, these data allow defining a model for the action of FAP at interfaces (Figure 9), similar to that of lipolytic enzymes(57). In this model, FAP has to bind first at the lipid-water interface before forming an interfacial Michaelis-Menten complex with its FA 
substrate and catalyzing its conversion into the hydrocarbon product. This latter is then released and can diffuse in the hydrophobic core of the oil droplet or the LUV bilayer.

However, and on the contrary to what is known for some lipases and phospholipases, we did not observed a drastic jump in FAP activity at interfaces versus bulk, the so-called "interfacial activation"(58). This is probably because the bulk conditions already correspond to a dispersion of insoluble FAs in water and not to a soluble monomeric substrate. Indeed, interfacial activation can only be observed with a partly soluble substrate once its solubility is exceeded and substrate aggregates displaying a lipid-water interface are formed (59). Therefore it is not possible to observe any interfacial activation of FAP using an insoluble substrate. Moreover, the kinetic phenomenon of interfacial activation has been observed only with a few lipolytic enzymes $(59,60)$ and it cannot be considered as a general characterictic of interfacial enzymes.

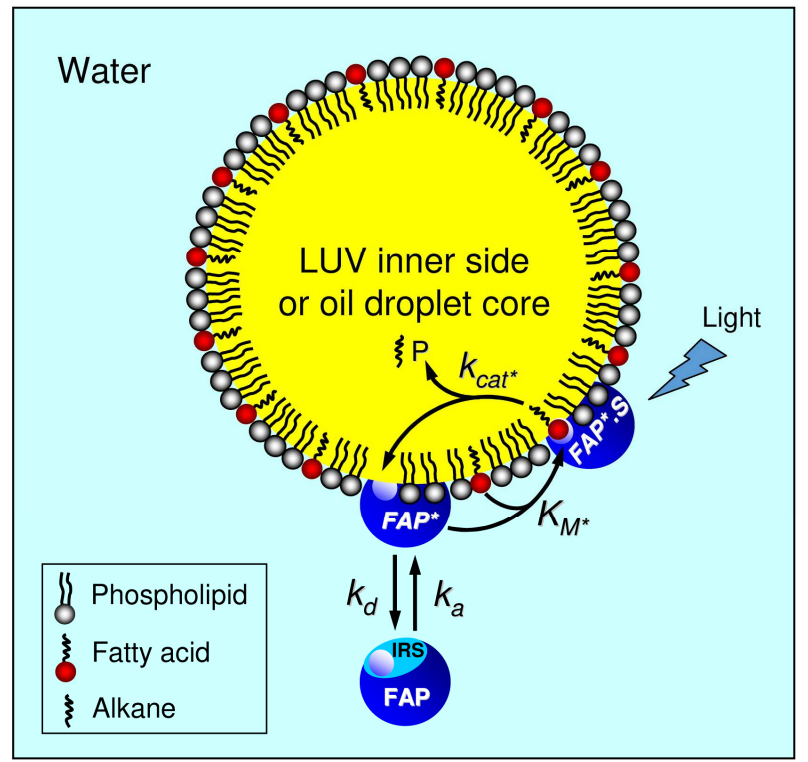

Figure 9. Schematic representation of FAP adsorption and activity on FAs at the surface of a phospholipid large unilamellar vesicle (LUV) or an oil (TAG) droplet covered by a phospholipid monolayer. This scheme is adapted from the Verger-De Haas' kinetic model for the action of a water-soluble lipolytic enzyme on an insoluble lipid substrate(57). FAP*, FAP bound at the lipidwater interface; FAP*.S, interfacial Michaelis-Menten complex of FAP with its FA substrate ( $\mathrm{S}=\mathrm{FA}$ ); $\mathrm{P}$, hydrocarbon product resulting from the decarboxylation of FA. P is presented as released in the hydrophobic core of the oil droplet. Alternatively, it may diffuse in the LUV membrane. $\mathrm{K}_{\mathrm{M}} *$ and $\mathrm{k}_{\mathrm{cat}}$ * are the interfacial MichaelisMenten constant and catalytic rate constant, respectively. $\mathrm{k}_{\mathrm{a}}$ and $\mathrm{k}_{\mathrm{d}}$ are the adsorption and desorption rate constants, respectively.

Since FAP has been shown to be active on C2 to C6 shortmedium chain FAs in vitro $(14,15)$, it seems that FAP can act on both soluble and insoluble substrates like some lipolytic enzymes found at the border between esterases and lipases, e. g. cutinase (59). However, from the data reported in literature, obtained using non-purified FAP, it is not possible to determine specific activities and whether a jump in activity occurs above the FA solubility. Specific experiments with increasing concentrations of a FA showing some solubility in water should be performed to demonstrate a putative interfacial activation of FAP. Nevertheless, since short-medium chain FA are not found in Chlorella variabilis from which FAP was isolated and since FAP was found to partition between the chloroplast stroma and thylakoid membranes(49), FAP is likely to act exclusively as an interfacial enzyme in vivo.

In lipases, interfacial activation has been associated with the opening of a lid covering the active site $(61,62)$. So far, there is no evidence of a lid in FAP nor of lipid-induced conformational changes that could give access to the active site. Nevertheless, the amphipathic helix $\alpha 13$ bordering the active site entrance and interacting with a FA molecule could adopt a different conformation in the absence of FA and its potential role should be further explored.

Besides these kinetic aspects, there is strong evidence for the presence of an IRS in the 3D structure of FAP (Figure 8), with clusters of hydrophobic and basic amino acids forming a plateau on the same side as the active site entrance. The concentration of positive charges on one side of the enzyme and the resulting dipolar moment suggest a possible orientation for FAP at interfaces. Since FAP activity is the highest at $\mathrm{pH}$ values at which FAs are ionized, it is now worth determining whether the ionization of FAs is essential for FAP interfacial binding in addition to its importance for the mechanism of fatty acid decarboxylation in the active site(36). Also, the role of the $\mathrm{N}$ terminal end of FAPv1, which has an effect on FAP binding at interfaces (Table 1) and activity (Figure 2), should be further investigated.

The fact that FAP can act on FA present at the surface of oil-inwater emulsions is particularly interesting since it is envisioned to use FAP in combination with lipases to produce hydrocarbons from vegetable oils $(19,63)$. Similarly, since FAP acts on FAs present at the surface of LUVs and shows a high affinity for phospholipid and galactolipid monolayers (Table 2), it could be combined with phospholipases and galactolipases acting on membrane lipids. The latter enzymes are very attractive to get access to the main stocks of fatty acids on Earth, i.e. the membranes of photosynthetic organisms(64). The use of controlled interfaces (microemulsions or LUV) for presenting the FA substrate to FAP, instead of uncontrolled FA dispersions made with organic solvents like DMSO, is an important step towards optimizing the combined action of FAP and lipolytic enzymes. It should favor the activity of these latter enzymes and pave the way to design improved processes using FAP as a biocatalyst.

In addition to potential applications, the present study provides valuable information on how FAP is likely to access its nonesterified fatty acid substrate in microalgal chloroplast membranes $(49,65)$. Indeed, one might have imagined that FAP could only access fatty acids as a monomer and via another protein partner (such as a lipase or a fatty acid transporter). However, we show here that FAP can recruit its substrate directly into a membrane and thus, has the capacity to act as an interfacial enzyme.

\section{ASSOCIATED CONTENT}

\section{Supporting Information}

The Supporting Information is available free of charge on the ACS Publications website.

Experimental procedures, Supplementary figures, Protein sequences as described in the text. (PDF) 


\section{AUTHOR INFORMATION}

\section{Corresponding Authors}

* Frédéric Carrière - Aix Marseille Université, CNRS, UMR 7281 Bioénergétique et Ingénierie des Protéines, Marseille, France ; http://orcid.org/0000-0003-4848-9418; carriere@imm.cnrs.fr;

* Fred Beisson - CEA, CNRS, Aix Marseille Université, Biosciences and Biotechnologies Institute of Aix-Marseille (BIAM), UMR 7265, CEA Cadarache, 13108 Saint-Paul-lez-Durance, France; https://orcid.org/0000-0001-9995-7387 ; Email: frederic.beisson@cea.fr ;

\section{Author Contributions}

C.A. performed all experiments, was involved in method validation, data curation, formal analysis, and writing - first draft, review and editing.

D.S. supported the production of FAP, FAP activity measurements, data curation and writing, review and editing.

B.L. analyzed the production of hydrocarbons by FAP, supported methodology for FAP activity measurements, and data curation.

A.B. supervised and supported monomolecular film experiments.

G.P. analyzed FAP structural properties and supported writing, review and editing.

F.B. and F.C. were equally involved in the conceptualization and supervision of this $\mathrm{PhD}$ work, data curation, formal analysis, and writing final manuscript.

All authors have given approval to the final version of the manuscript

\section{Funding Sources}

The $\mathrm{PhD}$ thesis of $\mathrm{C}$. Aselmeyer was supported jointly by Aix Marseille Université (AMU) and Commissariat à l'énergie atomique et aux énergies alternatives (CEA), France. Financial support of CEA to F. Beisson (DRF Impulsion program) is also acknowledged. D. Sorigué thanks P. Chagvardieff and CEA for financial support.

\section{Notes}

The authors declare no conflict of interest.

\section{ACKNOWLEDGMENTS}

Excellent technical help of S. Blangy and S. Cuiné (BIAM) for FAP purification is acknowledged.

\section{ABBREVIATIONS}

BSA, bovine serum albumin; C12-DGDG, di-galactosyl-didodecanoyl-glycerol; FAP, fatty acid photodecarboxylase; FA, fatty acid; IRS, interfacial recognition site; LUV, large unilamellar vesicle; NaTDC, sodium taurodeoxycholate; PA, palmitic acid; PC, phosphatidylcholine

\section{REFERENCES}

1. Jetter, R., and Kunst, L. (2008) Plant surface lipid biosynthetic pathways and their utility for metabolic engineering of waxes and hydrocarbon biofuels, Plant J 54, 670-683

2. Jimenez-Diaz, L., Caballero, A., Perez-Hernandez, N., and Segura, A. (2017) Microbial alkane production for jet fuel industry: motivation, state of the art and perspectives, Microb Biotechnol 10, 103-124.

3. Herman, N. A., and Zhang, W. (2016) Enzymes for fatty acid-based hydrocarbon biosynthesis, Curr Opin Chem Biol 35, 22-28.

4. Liu, K., and Li, S. (2020) Biosynthesis of fatty acid-derived hydrocarbons: perspectives on enzymology and enzyme engineering, Curr Opin Biotechnol 62, 7-14.

5. Jaroensuk, J., Intasian, P., Wattanasuepsin, W., Akeratchatapan, N., Kesornpun, C., Kittipanukul, N., and Chaiyen, P. (2020) Enzymatic reactions and pathway engineering for the production of renewable hydrocarbons, J Biotechnol 309, 1-19.

6. Rude, M. A., Baron, T. S., Brubaker, S., Alibhai, M., Del Cardayre, S. B., and Schirmer, A. (2011) Terminal olefin (1-alkene) biosynthesis by a novel p450 fatty acid decarboxylase from Jeotgalicoccus species, Appl Environ Microbiol 77, 1718-1727.

7. Andre, C., Kim, S. W., Yu, X. H., and Shanklin, J. (2013) Fusing catalase to an alkane-producing enzyme maintains enzymatic activity by converting the inhibitory byproduct $\mathrm{H} 2 \mathrm{O} 2$ to the cosubstrate O2, Proc Natl Acad Sci U S A 110, 3191-3196.

8. Rui, Z., Li, X., Zhu, X., Liu, J., Domigan, B., Barr, I., Cate, J. H., and Zhang, W. (2014) Microbial biosynthesis of medium-chain 1alkenes by a nonheme iron oxidase, Proc Natl Acad Sci U S A 111, 18237-18242.

9. Zhang, J., Lu, X., and Li, J. J. (2013) Conversion of fatty aldehydes into alk (a/e)nes by in vitro reconstituted cyanobacterial aldehyde-deformylating oxygenase with the cognate electron transfer system, Biotechnol Biofuels 6, 86 .

10. Sorigue, D., Legeret, B., Cuine, S., Blangy, S., Moulin, S., Billon, E., Richaud, P., Brugiere, S., Coute, Y., Nurizzo, D., Muller, P., Brettel, K., Pignol, D., Arnoux, P., Li-Beisson, Y., Peltier, G., and Beisson, F. (2017) An algal photoenzyme converts fatty acids to hydrocarbons, Science 357, 903-907.

11. Sancar, A. (2003) Structure and function of DNA photolyase and cryptochrome blue-light photoreceptors, Chem Rev 103, 2203-2237.

12. Zhang, S., Heyes, D. J., Feng, L., Sun, W., Johannissen, L. O., Liu, H., Levy, C. W., Li, X., Yang, J., Yu, X., Lin, M., Hardman, S. J. O., Hoeven, R., Sakuma, M., Hay, S., Leys, D., Rao, Z., Zhou, A., Cheng, Q., and Scrutton, N. S. (2019) Structural basis for enzymatic photocatalysis in chlorophyll biosynthesis, Nature 574, 722-725.

13. Björn, L. O. (2015) Photoactive proteins, In Photobiology, The science of light and life (Björn, L. O., Ed.), pp 139-150, SpringerVerlag New York.

14. Zhang, W., Ma, M., Huijbers, M. M. E., Filonenko, G. A., Pidko, E. A., van Schie, M., de Boer, S., Burek, B. O., Bloh, J. Z., van Berkel, W. J. H., Smith, W. A., and Hollmann, F. (2019) Hydrocarbon Synthesis via Photoenzymatic Decarboxylation of Carboxylic Acids, $J$ Am Chem Soc 141, 3116-3120.

15. Amer, M., Wojcik, E. Z., Sun, C., Hoeven, R., Hughes, J. M. X., Faulkner, M., Yunus, I. S., Tait, S., Johannissen, L. O., Hardman, S. J. O., Heyes, D. J., Chen, G.-Q., Smith, M. H., Jones, P. R., Toogood, H. S., and Scrutton, N. S. (2020) Low carbon strategies for sustainable bio-alkane gas production and renewable energy, Energy \& Environmental Science 13, 1818-1831.

16. Yunus, I. S., Wichmann, J., Wordenweber, R., Lauersen, K. J., Kruse, O., and Jones, P. R. (2018) Synthetic metabolic pathways for photobiological conversion of $\mathrm{CO} 2$ into hydrocarbon fuel, Metab Eng $49,201-211$

17. Bruder, S., Moldenhauer, E. J., Lemke, R. D., LedesmaAmaro, R., and Kabisch, J. (2019) Drop-in biofuel production using fatty acid photodecarboxylase from Chlorella variabilis in the oleaginous yeast Yarrowia lipolytica, Biotechnol Biofuels 12, 202.

18. Moulin, S., Legeret, B., Blangy, S., Sorigue, D., Burlacot, A., Auroy, P., Li-Beisson, Y., Peltier, G., and Beisson, F. (2019) Continuous photoproduction of hydrocarbon drop-in fuel by microbial cell factories, Sci Rep 9, 13713 .

19. Huijbers, M. M. E., Zhang, W., Tonin, F., and Hollmann, F. (2018) Light-Driven Enzymatic Decarboxylation of Fatty Acids, Angew Chem Int Ed Engl 57, 13648-13651.

20. Ma, Y., Zhang, X., Zhang, W., Li, P., Li, Y., Hollmann, F., and Wang, Y. (2020) Photoenzymatic Production of Next Generation Biofuels from Natural Triglycerides Combining a Hydrolase and a Photodecarboxylase, ChemPhotoChem 4, 39-44.

21. Xu, J., Hu, Y., Fan, J., Arkin, M., Li, D., Peng, Y., Xu, W., Lin, X., and Wu, Q. (2019) Light-Driven Kinetic Resolution of alphaFunctionalized Carboxylic Acids Enabled by an Engineered Fatty Acid Photodecarboxylase, Angew Chem Int Ed Engl 58, 8474-8478.

22. Zhang, W., Lee, J. H., Younes, S. H. H., Tonin, F., 3 Hagedoorn, P. L., Pichler, H., Baeg, Y., Park, J. B., Kourist, R., and 
Hollmann, F. (2020) Photobiocatalytic synthesis of chiral secondary fatty alcohols from renewable unsaturated fatty acids, Nat Commun 11, 2258.

23. Cha, H. J., Hwang, S. Y., Lee, D. S., Kumar, A. R., Kwon, Y. U., Voss, M., Schuiten, E., Bornscheuer, U. T., Hollmann, F., Oh, D. K., and Park, J. B. (2020) Whole-Cell Photoenzymatic Cascades to Synthesize Long-Chain Aliphatic Amines and Esters from Renewable Fatty Acids, Angew Chem Int Ed Engl 59, 7024-7028.

24. Mukerjee, P. (1965) Dimerization of Anions of Long-Chain Fatty Acids in Aqueous Solutions and the Hydrophobic Properties of the Acids., J. Phys. Chem. 69, 2821-2827.

25. Douliez, J. P., Navailles, L., and Nallet, F. (2006) Selfassembly of fatty acid-alkylboladiamine salts, Langmuir 22, 622-627.

26. Douliez, J. P., Gaillard, C., Navailles, L., and Nallet, F. (2006) Novel lipid system forming hollow microtubes at high yields and concentration, Langmuir 22, 2942-2945.

27. Gaillard, C., Novales, B., Jérôme, F., and Douliez, J. P. (2008) Broad Polymorphism of Fatty Acids with Amino Organosilane Counterions, Towards Novel Templates., Chemistry of Materials 20, 1206-1208.

28. Morigaki, K., and Walde, P. (2007) Fatty acid vesicles, Current Opinion in Colloid \& Interface Science 12, 75-80.

29. Cistola, D. P., Hamilton, J. A., Jackson, D., and Small, D. M. (1988) Ionization and Phase Behavior of Fatty Acids in Water: Application of the Gibbs Phase Rule., Biochemistry 27, 1881-1888.

30. Small, D. M. (1968) A classification of biological lipids based upon their interaction in aqueous systems, J. Amer. Oil Chem. Soc. 45, 108-119.

31. Smith, A., and Lough, A. K. (1976) Micellar solubilization of fatty acids in aqueous media containing bile salts and phospholipids, $\mathrm{Br}$ J Nutr 35, 77-87.

32. Cistola , D. P., Atkinson, D., Hamilton, J. A., and Small, D. M. (1986) Phase Behavior and Bilayer Properties of Fatty Acids: Hydrated 1:1 Acid-Soaps., Biochemistry 25, 2804-2812.

33. Kanicky, J. R., Poniatowski, A. F., Mehta, N. R., and Shah, D. O. (2000) Cooperativity among Molecules at Interfaces in Relation to Various Technological Processes: Effect of Chain Length on the pKa of Fatty Acid Salt Solutions, Langmuir 16, 172-177.

34. Kanicky, J. R., and Shah, D. O. (2003) Effect of Premicellar Aggregation on the pKa of Fatty Acid Soap Solutions, Langmuir 19, 2034-2038.

35. Lafont, D., Carriere, F., Ferrato, F., and Boullanger, P. (2006) Syntheses of an alpha-D-Gal-(1-->6)-beta-D-Gal diglyceride, as lipase substrate, Carbohydr Res 341, 695-704.

36. Sorigué, D., Hadjidemetriou, K., Blangy, S., Gotthard, G., Bonvalet, A., Coquelle, N., Samire, P., Aleksandrov, A., Antonucci, L., Benachir, A., Boutet, S., Byrdin, M., Cammarata, M., Carbajo, S., Cuiné, S., Doak, R. B., Foucar, L., Gorel, A., Grünbein, M., Hartmann, E., Hienerwadel, R., Hilpert, M., Kloos, M., Lane, T. J., Légeret, B., Legrand, P., Li-Beisson, Y., Moulin, S. L. Y., Nurizzo, D., Peltier, G., Schirò, G., Shoeman, R. L., Sliwa, M., Solinas, X., Zhuang, B., Barends, T. R. M., Colletier, J.-P., Joffre, M., Royant, A., Berthomieu, C., Weik, M., Domratcheva, T., Brettel, K., Vos, M. H., Schlichting, I., Arnoux, P., Müller, P., and Beisson, F. (2021) Mechanism and dynamics of fatty acid photodecarboxylase, Science 372, eabd568.

37. Benarouche, A., Sams, L., Bourlieu, C., Vie, V., Point, V., Cavalier, J. F., and Carriere, F. (2017) Studying Gastric Lipase Adsorption Onto Phospholipid Monolayers by Surface Tensiometry, Ellipsometry, and Atomic Force Microscopy, Methods Enzymol 583, 255-278.

38. Amara, A., Lafont, D., Parsiegla, G., Point, V., Chabannes, A., Rousset, A., and Carrière, F. (2013) The galactolipase activity of some microbial lipases and pancreatic enzymes., Eur. J. Lipid Sci. Technol. 115, 442-451.

39. Schrodinger, L. L. C. (2010) The PyMOL Molecular Graphics System, 1.3 ed.

40. Felder, C. E., Prilusky, J., Silman, I., and Sussman, J. L. (2007) A server and database for dipole moments of proteins, Nucleic Acids Res 35, W512-521.

41. Scow, R. O., and Blanchette-Mackie, E. J. (1985) Why fatty acids flow in cell membranes, Prog Lipid Res 24, 197-241.

42. Skulj, S., and Vazdar, M. (2019) Calculation of apparent pKa values of saturated fatty acids with different lengths in DOPC phospholipid bilayers, Phys Chem Chem Phys 21, 10052-10060.

43. Egret-Charlier, M., Sanson, A., Ptak, M., and Bouloussa, O. (1978) Ionization of fatty acids at the lipid-water interface, FEBS Lett $89,313-316$

44. Zuidam, N. J., Gouw, H. K., Barenholz, Y., and Crommelin, D. J. (1995) Physical (in) stability of liposomes upon chemical hydrolysis: the role of lysophospholipids and fatty acids, Biochim Biophys Acta 1240, 101-110.

45. Lhor, M., Methot, M., Horchani, H., and Salesse, C. (2015) Structure of the N-terminal segment of human retinol dehydrogenase 11 and its preferential lipid binding using model membranes, Biochim Biophys Acta 1848, 878-885.

46. Point, V., Benarouche, A., Jemel, I., Parsiegla, G., Lambeau, G., Carriere, F., and Cavalier, J. F. (2013) Effects of the propeptide of group $\mathrm{X}$ secreted phospholipase $\mathrm{A}(2)$ on substrate specificity and interfacial activity on phospholipid monolayers, Biochimie 95, 51-58.

47. Carasso, M. L., Rowlands, W. N., and Kennedy, R. A. (1995) Electroacoustic Determination of Droplet Size and Zeta Potential in Concentrated Intravenous Fat Emulsions, Journal of Colloid and Interface Science 174, 405-413.

48. Benzonana, G., and Desnuelle, P. (1965) Kinetic study of the action of pancreatic lipase on emulsified triglycerides. Enzymology assay in heterogeneous medium., Biochim. Biophys. Acta 105, 121-136.

49. Moulin, S. L. Y., Beyly-Adriano, A., Cuiné, S., Blangy, S., Légeret, B., Floriani, M., Burlacot, A., Sorigué, D., Samire, P.-P., LiBeisson, Y., Peltier, G., and Beisson, F. (2021) Fatty acid photodecarboxylase is an ancient photoenzyme that forms hydrocarbons in the thylakoids of algae, Plant Physiology in press.

50. Marsh, D. (1996) Lateral pressure in membranes., Biochim Biophys Acta 1286, 183-223.

51. Demel, R. A., Geurts van Kessel, W. S. M., Zwaal, R. F. A., Roelofsen, B., and van Deenen, L. M. (1975) Relation between various phospholipase actions on human red cell membranes and the interfacial phospholipid pressure in monolayers, Biochim. Biophys. Acta 406, 97107.

52. Benarouche, A., Point, V., Carriere, F., and Cavalier, J. F. (2014) An interfacial and comparative in vitro study of gastrointestinal lipases and Yarrowia lipolytica LIP2 lipase, a candidate for enzyme replacement therapy, Biochimie 102, 145-153.

53. De la Fournière, L., Ivanova, M. G., Blond, J.-P., Carrière, F., and Verger, R. (1994) Surface behaviour of human pancreatic and gastric lipases, Colloids Surf B Biointerfaces 2, 585-593.

54. Mateos-Diaz, E., Amara, S., Roussel, A., Longhi, S., Cambillau, C., and Carriere, F. (2017) Probing Conformational Changes and Interfacial Recognition Site of Lipases With Surfactants and Inhibitors, Methods Enzymol 583, 279-307.

55. Canaan, S., Nielsen, R., Ghomashchi, F., Robinson, B. H., and Gelb, M. H. (2002) Unusual mode of binding of human group IIA secreted phospholipase A2 to anionic interfaces as studied by continuous wave and time domain electron paramagnetic resonance spectroscopy, J Biol Chem 277, 30984-30990.

56. Nitenberg, M., Makshakova, O., Rocha, J., Perez, S., Marechal, E., Block, M. A., Girard-Egrot, A., and Breton, C. (2020) Mechanism of activation of plant monogalactosyldiacylglycerol synthase 1 (MGD1) by phosphatidylglycerol, Glycobiology 30, 396406 .

57. Verger, R., and de Haas, G. H. (1976) Interfacial enzyme kinetics of lipolysis, Annual Review Biophys. Bioeng. 5, 77-117.

58. Sarda, L., and Desnuelle, P. (1958) Action de la lipase pancréatique sur les esters en émulsion, Biochim. Biophys. Acta 30, $513-521$

59. Ferrato, F., Carriere, F., Sarda, L., and Verger, R. (1997) A critical reevaluation of the phenomenon of interfacial activation, Methods Enzymol 286, 327-347.

60. Pieterson, W. A., Vidal, J. C., Volwerk, J. J., and de Haas, G. H. (1974) Zymogen-catalysed hydrolysis of monomeric substrates and the presence of a recognition site for lipid-water interfaces in phospholipase A2., Biochemistry 13, 1455-1460.

61. van Tilbeurgh, H., Egloff, M.-P., Martinez, C., Rugani, N., Verger, R., and Cambillau, C. (1993) Interfacial activation of the lipaseprocolipase complex by mixed micelles revealed by X-Ray 
62. Brzozowski, A. M., Derewenda, U., Derewenda, Z. S.,

64. Gounaris, K., and Barber, J. (1983) Dodson, G. G., Lawson, D. M., Turkenburg, J. P., Bjorkling, F., Huge- Monogalactosyldiacylglycerol: the most abundant polar lipid in nature., Jensen, B., Patkar, S. A., and Thim, L. (1991) A model for interfacial activation in lipases from the structure of a fungal lipase-inhibitor complex, Nature 351, 491-494.

63. Ozgen, F. F., Runda, M. E., and Schmidt, S. (2021) Photobiocatalytic Cascades: Combining Chemical and Enzymatic Trends Biochem. Sci. 8, 378-381.

65. Sorigue, D., Legeret, B., Cuine, S., Morales, P., Mirabella, B., Guedeney, G., Li-Beisson, Y., Jetter, R., Peltier, G., and Beisson, F. (2016) Microalgae Synthesize Hydrocarbons from Long-Chain Fatty Transformations Fueled by Light, Chembiochem 22, 790-806. 